NBER WORKING PAPER SERIES

\title{
EFFICIENCY COSTS OF MEETING INDUSTRY-DISTRIBUTIONAL CONSTRAINTS UNDER ENVIRONMENTAL PERMITS AND TAXES
}

\author{
A. Lans Bovenberg \\ Lawrence H. Goulder \\ Derek J. Gurney \\ Working Paper 10059 \\ http://www.nber.org/papers/w10059
NATIONAL BUREAU OF ECONOMIC RESEARCH 1050 Massachusetts Avenue
Cambridge, MA 02138
October 2003

We are grateful to Dallas Burtraw, Ian Parry, Billy Pizer, Kerry Smith, and seminar participants at the NBER Summer Institute Workshop on Public Policy and the Environment for helpful comments. We also thank Mark Jacobsen for excellent research assistance and the William and Flora Hewlett Foundation and National Science foundation (grant SES-0112102) for financial support. The views expressed herein are those of the authors and not necessarily those of the National Bureau of Economic Research.

(C)2003 by A. Lans Bovenberg Lawrence H. Goulder, and Derek J. Gurney. All rights reserved. Short sections of text, not to exceed two paragraphs, may be quoted without explicit permission provided that full credit, including (C) notice, is given to the source. 
Efficiency Costs of Meeting Industry-Distributional Constraints under Environmental Permits and Taxes

A. Lans Bovenberg and Lawrence H. Goulder, and Derek J. Gurney NBER Working Paper No. 10059

October 2003

JEL No. H22, H23, D50, D58

\section{ABSTRACT}

A politically realistic approach to environmental policy seems to require avoiding significant profitlosses in major pollution-related industries. The government can avoid such losses by freely allocating some emissions permits or by exempting some inframarginal emissions from a pollution tax. However, preventing profit-losses in this way involves an efficiency cost because it compels the government to forego especially efficient sources of revenue and to rely more heavily on ordinary, distortionary taxes. Using analytically and numerically solved equilibrium models, we analyze these efficiency costs.

We find that when the required amount of abatement is small, the efficiency cost implied by the profits-constraint dwarfs the other efficiency costs of pollution-control. When the abatement requirement becomes more extensive, the cost of this constraint diminishes relative to the other efficiency costs. We also calculate and analyze the determinants of the "gross compensation ratio" - the share of pollution permits that must be freely allocated to prevent profit-losses in the targeted industries. Numerical simulations of sulfur dioxide pollution-control suggest that the Bush Administration's Clear Skies Initiative would exceed this ratio, freely allocating more permits than necessary to preserve profits.

$\begin{array}{lll}\text { A.L. Bovenberg } & \text { Lawrence H. Goulder } & \text { Derek J. Gurney } \\ \text { Department of Economics } & \text { Department of Economics } & \text { Department of Economics } \\ \text { and CentER } & \text { Landau Building } & \text { Landau Building } \\ \text { Tilburg University } & \text { Stanford University } & \text { Stanford University } \\ \text { 5000 LE Tilburg } & \text { Stanford, CA 94305 } & \text { Stanford, CA 94305 } \\ \text { The Netherlands } & \text { and NBER } & \text { derek.gurney@stanford.edu } \\ \text { a.l.bovenberg@uvt.nl } & \text { goulder@stanford.edu } & \end{array}$




\section{Introduction}

In evaluating environmental policies, economists tend to emphasize efficiency and costeffectiveness. Yet the distributional impacts of policies clearly are highly relevant to social welfare, and such impacts often critically influence political feasibility. Distributional effects can be measured along a number of dimensions - across household income groups, geographic regions, generations, and industries. An especially important dimension is the potential distribution of impacts across domestic industries. This reflects the fact that industry groups constitute a powerful political force. ${ }^{1}$

The degree to which environmental policies impose burdens on given industries is closely related to the capacity of these policies to generate public revenues or private rents. Some policies generate considerable public revenue - these policies include emissions taxes, fuel taxes, and systems of tradable permits in which the government initially allocates the permits through an auction. These revenue-generating policies tend to impose a large share of the economy-wide burden of regulation on the polluting firms. Under these policies, firms not only incur abatement costs but also must pay for inframarginal pollution: they must either pay pollution taxes on such emissions or purchase pollution permits giving them the right to generate such emissions. In effect, these policies transfer property rights from firms to the public sector, reclaiming from firms the ownership of environmental resources such as air quality. The changes in property rights can have substantial distributional impacts and can thus generate considerable political opposition from the adversely affected parties.

To the extent that industrial stakeholders wield substantial political power, designing policies that achieve environmental goals while avoiding serious adverse impacts on key industries can enhance political feasibility. ${ }^{2}$ One way to reduce the burden on the polluting industries is to allow firms to retain a portion of the potential revenues. For

\footnotetext{
${ }^{1}$ The significant influence of industry groups in the political process can be explained in various ways. One influential explanation was articulated by Mancur Olson (1965), who argued that the degree of political mobilization of interest groups depends on the concentration of the impact of the potential policy. Concentrated potential costs alleviate free-rider problems in lobbying efforts and thus may result in significant contributions of time and other resources to become engaged in the political process. If costs are sufficiently concentrated relative to benefits, therefore, the agents who would face these costs can exert greater influence on the political process than those who would enjoy the widely dispersed benefits and thus face more serious free-rider problems. This holds even if aggregate benefits exceed aggregate costs.

${ }^{2}$ Shifting the burden in this way offers potential attractions beyond political feasibility. To the extent that the government avoids producing unexpected adverse distributional impacts in its environmental
} 
example, the government could introduce a system of tradable permits in which permits are not auctioned but instead are given out free (or "grandfathered") on the basis of historical presence in the affected industry. In this case, regulated firms retain as rents what otherwise would have become government revenue from the sale of permits. Firms pay only for whatever pollution they would produce beyond what is implied by their initial permit allotment. Likewise, the government could introduce an emissions tax policy with an exemption for some inframarginal emissions. Here firms retain as rent what would otherwise have been a tax payment for inframarginal emissions.

These policies suffer little or no disadvantage on environmental grounds. Firms continue to face higher costs for pollution at the margin - each additional unit of pollution requires either the purchase of an additional permit or an increase in the pollution tax payment - and thus they are encouraged to cut pollution. But insulating firms through grandfathering of permits or exemptions to emissions taxes carries an efficiency cost because the government forgoes permit revenue or emission-tax revenue and thus must rely more on ordinary distortionary taxes (such as income or sales taxes) to raise revenues. This reduces efficiency because the foregone revenue is inframarginal and therefore would have yielded revenue at lower efficiency cost than ordinary taxes. ${ }^{3} \mathrm{Al}-$ leviating the adverse distributional impact on particular polluting firms thus comes at a cost in terms of efficiency. ${ }^{4}$

This paper examines the efficiency costs of avoiding adverse industry-distributional effects under environmental taxes and quotas. We identify the determinants of the added cost relative to the cost in the absence of a constraint on distributional impacts. Related to this added cost is the compensation ratio - the share of potential revenue that the government must forego to protect the industries in question. We distinguish gross and net compensation ratios, where the net ratio takes account of the policy's adverse impact on the revenue yield from existing distortionary taxes and thus provides information on the capacity of policies to raise net revenues. ${ }^{5}$ We examine how these ratios are inititatives, it helps to ensure stable property rights and thereby cultivates a reputation as an impartial guardian of investors' rights. This can enhance the investment climate and dynamic efficiency.

${ }^{3}$ This efficiency issue has been explored in previous papers comparing the costs of policies that differ in terms of whether they charge for inframarginal emissions. See, for example, Goulder et al. (1999), Parry and Oates (2000), and Fullerton and Metcalf (2001).

${ }^{4}$ There would be little or no added efficiency cost if the government could obtain the foregone revenue through lump-sum taxes or some other tax which, if increased, would reduce overall distortions of the tax system.

${ }^{5}$ The reduction in revenue-yield reflects the policy-induced erosion of the factor tax base (reduction in factor supply). Smith, Ross, and Montgomery (2002) consider the significance of this phenomenon. 
influenced by the stringency of the environmental policy, the production technology, and demand.

We investigate these issues using a general framework that can consider a wide range of pollution-control settings. Earlier work by Bovenberg and Goulder (2001), by Smith, Ross, and Montgomery (2002), and by Burtraw et al. (2002) investigated these issues in the context of $\mathrm{CO}_{2}$ emissions policy. ${ }^{6}$ The present investigation generalizes the earlier work in several ways. First, we extend the analysis to make it applicable not only to $\mathrm{CO}_{2}$ but to other forms of pollution as well. In the earlier studies, demanders of pollutionrelated (namely, fossil) fuels could reduce the emissions-output ratio only through inputsubstitution (for example, switching from coal to natural gas). This restriction is appropriate when the focus is on $\mathrm{CO}_{2}$ emission-reductions, since at present ${ }^{7}$ inputsubstitution appears to be the only significant channel for reducing the $\mathrm{CO}_{2}$ emissionsoutput ratio. However, end-of-pipe treatment - the installation of equipment to filter, treat, or remove emissions as they move through the smokestack - is an important channel through which other pollutants can be reduced. This study considers this additional channel as well, and thus we are able to apply our model to policies aimed at other pollutants besides $\mathrm{CO}_{2}$.

A second difference is that we employ both analytical and numerical models to generate our results: the previous studies applied only a numerical model. Our analytical model enables us to obtain general results regarding the determinants of efficiency impacts and the distribution of policy costs. These results are then evaluated quantitatively with the numerical model.

A third difference is the integrated focus on downstream and upstream pollutiongenerating industries. While the previous Bovenberg-Goulder study concentrated on the problem of avoiding adverse impacts on "upstream" industries — the industries that supply fossil fuels - here we consider in addition the downstream industries, that is, the industries that utilize the fuels or other inputs associated with pollution. "Downstream policies" are a central feature of several recent legislative proposals. The Bush Administration, Senator James Jeffords, and Senator Thomas Carper have each introduced bills to "cap and trade" emissions of various pollutants from U.S. electric power plants. The

\footnotetext{
${ }^{6}$ For an excellent review of compensation issues in the context of U.S. $\mathrm{CO}_{2}$ policy, see Dinan (2003).

${ }^{7}$ Scientists currently are investigating possibilities for end-of-pipe treatment of carbon dioxide emissions through carbon separation and geological sequestration. Eventually this may emerge as a significant channel for $\mathrm{CO}_{2}$ emissions reduction. At present, however, this approach is very costly and it has been applied only on a very limited basis. See Anderson and Newell (2003).
} 
Administration bill applies to sulfur dioxide, nitrogen oxides, and mercury; the other two bills target these emissions and carbon dioxide as well. In addition, the European Union is committed to introducing, on a Europe-wide basis, a system of tradable permits applied to several downstream industries, including electric power, steel, cement, and aluminum manufacturing.

We find, in both models, that the efficiency cost from the compensation constraint rises with the extent of required pollution abatement. However, as the abatement requirement becomes more extensive, the cost of this constraint diminishes relative to the other efficiency costs of pollution-control. The degree of availability of end-of-pipe treatment can significantly reduce overall policy costs in absolute terms. At the same time, the availability of such treatment has little impact on the relative increase in efficiency cost imposed by the compensation constraint.

We also find that both the gross and net compensation ratios rise with the extent of required pollution abatement. In numerical simulations of sulfur dioxide pollutioncontrol, the gross compensation ratio tends to rise fairly slowly with abatement. Unless required abatement exceeds 75 percent, compensating the electric utilities industry requires free allocation of less than 50 percent of emissions permits. Numerical simulations of sulfur dioxide pollution-control suggest that the Bush Administration's Clear Skies Initiative would exceed this ratio, freely allocating more permits than necessary to preserve profits. Our models also highlight significant differences between gross and net policy revenues: when abatement is extensive, a large fraction of the revenue collected from emissions permits or taxes is offset by the revenue-loss from erosion of the base of existing factor taxes.

The rest of the paper is organized as follows. The following section presents the analytical model and derives and interprets its results. The analytical results stem from linear approximations; hence they are not necessarily valid for large policy changes. In addition, the analytical model assumes that the regulated pollution-supplying industries are very small compared to the economy as a whole, so that general equilibrium effects on the prices of mobile production factors can be ignored. Section III describes and applies a numerical model, whose results extend and quantify those of the analytical model. Since its solution does not require linear approximations, the numerical model is capable of investigating large policy changes. And because it relaxes the assumption that the regulated industries are small, this model allows for an assessment of general equilibrium effects. Section IV offers conclusions. The appendix provides details on the analytical solution. 


\section{An Analytical Model}

We develop a simple equilibrium model aimed at capturing the impact of environmental policy on an "upstream" industry supplying a pollution-generating product (e.g., a fuel) and a "downstream" industry demanding that product as an intermediate input.

There are two primary factors of production, capital $(K)$ and labor $(L)$. Capital is treated as imperfectly mobile across industries, labor as perfectly mobile. The model distinguishes three industries: the upstream industry, which produces an intermediate good $X$ associated with pollution, the downstream industry, which produces a final good $Y$, and the "other good" industry, which produces another final good $C$ enjoyed by consumers.

The downstream industry produces pollution emissions $E$ when it uses the intermediate input $X$ produced by the upstream industry. The downstream industry can influence the amount of pollution it generates both by changing its input mix (substituting other factors for $X$ ) and by engaging in end-of-pipe treatment.

A representative household's utility is a positive function of its consumption of $Y$ and $C$ and a negative function of its factor supplies and the economy's total emissions E.

\subsection{Production}

The upstream industry produces the intermediate good $X$ according to the following constant-returns-to-scale production function

$$
X=f_{x}\left(L_{x}, K_{x}\right)
$$

where $L_{x}$ denotes employment in the upstream industry and $K_{x}$ stands for the capital stock in that industry. Competitive maximizing behavior yields

$$
\begin{aligned}
& P_{x} \frac{\delta f_{x}(. ; .)}{\delta L_{x}}=W, \\
& P_{x} \frac{\delta f_{x}(. ; .)}{\delta K_{x}}=R_{x},
\end{aligned}
$$

where $P_{x}$ denotes the price of the intermediate good, $W$ the wage rate, and $R_{x}$ is the

rental rate of capital in the upstream sector. Since capital is imperfectly mobile, the rental rate can differ across industries. The wage rate, in contrast, is the same in both industries in keeping with the assumption of perfectly mobile labor. 
The downstream industry produces the final good $Y$. This industry is the only source of demand for the output of the upstream industry. The constant-returns-toscale production function of the downstream industry is given by

$$
Y=f_{y}\left(K_{y}, X, L_{y}\right)=h\left(v\left(K_{y} ; X\right) ; L_{y}\right),
$$

where $L_{y}$ stands for employment engaged in production in the downstream industry and $K_{y}$ is the capital stock in that industry. The production function is weakly separable. In particular, the substitution elasticity between the intermediate input $X$ and capital $K_{y}$ does not depend on industry-specific employment $L_{y}$; the intermediate input and capital first yield the composite $v\left(K_{y} ; X\right)$, which in turn is combined with labor to yield output $Y$.

The use of the intermediate input by the downstream industry causes pollution. This pollution can be reduced, however, by devoting resources to "end-of-pipe" treatment. Emissions, $E$, are given by

$$
E=e\left(X, g\left(C_{a} ; Y_{a}\right)\right)
$$

with $d e / d X \geq 0 ; d e / d g \leq 0 ; d g / d C_{a} \geq 0 ; d g / d Y_{a} \geq 0$. The subfunction $g$ is a composite of the two final goods $C_{a}$ and $Y_{a}$; it is an index of resources devoted to end-of-pipe treatment. $^{8}$ The downstream industry can thus reduce emissions per unit of output through either input substitution or end-of-pipe treatment.

Pure profits in the downstream industry are given by $P_{y} Y-P_{x} X-T_{e} E-W L_{y}-$ $P_{c} C_{a}-P_{y} Y_{a}-R_{y} K_{y}$, where $P_{y}$ represents the price of the final good produced by the downstream industry, $P_{c}$ the price of the other, clean final good, $R_{y}$ the rental rate of capital in the downstream industry, and $T_{e}$ the opportunity costs of emissions. This latter shadow cost can be interpreted as the tax rate on emissions. The downstream industry maximizes profits taking prices as given. ${ }^{9}$

\subsection{Supply of primary factors}

We employ the following transformation function to formalize the supply of sectorspecific capital services

$$
k\left(K_{x} ; K_{y} ; K_{c}\right)=K,
$$

\footnotetext{
${ }^{8}$ The emissions function $e(.,$.$) and the function g(.,$.$) exhibit constant returns to scale in their$ arguments. The function $g(.,$.$) also aggregates the goods C$ and $Y$ in the utility function (see (8) below).

${ }^{9}$ For the first-order conditions, see the Appendix.
} 
where $K$ represents the economy-wide stock of capital and $K_{c}$ stands for the capital stock in the "rest of the economy" (that is, the economy except for the upstream and downstream industries). The capital stock $K_{c}$ is used to produce a clean final good $C$ - the other final good in the economy. We capture imperfect mobility of capital (i.e., capital adjustment costs) by assuming that the substitution elasticities between the three types of capital are less than infinite. ${ }^{10}$

With perfectly mobile labor, labor market equilibrium is given by

$$
L=L_{x}+L_{y}+L_{c}
$$

where $L$ and $L_{c}$ respectively represent aggregate labor supply and labor employed in the sector producing the clean final good $C$.

\subsection{Household utility}

Households obtain utility from consumption of $Y$ and $C$. Aggregate emissions $E$, labor supply $L$, and capital supply $K$ produce disutility. ${ }^{11}$ Households choose $Y$ and $C$ to maximize the utility function

$$
U=w[v(g(Y, C), z(K, L)), E]
$$

with $\frac{\delta g}{\delta Y}, \frac{\delta g}{\delta C}, \frac{\delta v}{\delta g}, \frac{\delta w}{\delta v}, \frac{\delta w}{\delta z}>0, \frac{\delta w}{\delta E}, \frac{\delta z}{\delta L}, \frac{\delta z}{\delta K}<0$. Since the utility function is weakly separable in environmental quality, such quality does not directly affect household decisions. ${ }^{12}$

Households collect labor income, which is taxed at a proportional rate $T$, and capital income, which is taxed at the same proportional tax rate $T$. Uniform tax rates on capital

\footnotetext{
${ }^{10}$ The supply function can be interpreted as a multi-product firm that uses aggregate capital as an input to produce three outputs: namely, the three capital stocks $K_{i}(i=x, y, c)$.

${ }^{11}$ In a fully dynamic model, the cost of supplying capital is current consumption foregone when resources are devoted to investment instead of consumption. We include capital in the utility function to account for the cost of capital supply in our static model, which does not deal with investment explicitly. An alternative interpretation of $K$ is as a production factor (like labor or entrepreneurship) that is imperfectly mobile across sectors. In this interpretation, $L$ is the mobile factor and $K$ is the imperfectly mobile factor.

${ }^{12}$ A more general formulation would relax the assumption of separability between environmental quality and other goods in utility. Empirical work exploits non-separabilities to gauge the value of environmental quality based on demands for marketed goods (see, for example, Freeman (1993) and Smith (2000)). It is not clear in which direction the assumption of separability might bias the results. The efficiency cost estimates of environmental policy presented below are biased upward (downward) to the extent that environmental quality reduces (raises) the marginal disutility of factor supply compared to the marginal utility of final consumption of produced commodities.
} 
and labor income are optimal, given that capital and labor are weakly separable in utility from consumption.

In what follows we apply two concepts for measuring the efficiency costs of distortionary taxation. The first, the marginal cost of public funds, is denoted by $\lambda$ and is given by (see appendix):

$$
\lambda=\left(\frac{1}{1-\varepsilon_{u}[T /(1-T)]}\right)
$$

where $\varepsilon_{u}$ denotes the uncompensated wage elasticity of labor supply. ${ }^{13}$ The marginal cost of public funds represents the cost in terms of household income of raising one additional dollar of government revenue spent on public goods that are separable in utility from private goods (so that public expenditure does not impact marginal rates of substitution in utility).

A related cost concept, the marginal excess burden, applies in case where the revenue is not spent on public goods but rather is returned to households as lump-sum transfers. As shown in the appendix, the expression for the marginal excess burden of the labor $\operatorname{tax}, \mu$, is

$$
\mu=\left(\frac{\varepsilon_{c}[T /(1-T)]}{1-\varepsilon_{u}[T /(1-T)]}\right)
$$

where $\varepsilon_{c}$ stands for the compensated wage elasticity of labor supply. As mentioned above, we assume that initial tax system is optimal from a non-environmental point of view so that marginal excess burden of the capital tax is the same as that of the labor tax. $^{14}$

\subsection{Equilibrium}

For small policy shocks, the model can be solved analytically by log-linearizing it around its initial equilibrium. Unless indicated otherwise, small letters stand for relative (percentage) changes of the variables denoted by the corresponding capital letters. Greek letters represent either elasticities or shares in the initial equilibrium. In solving the

\footnotetext{
${ }^{13}$ This is the partial equilibrium concept of the marginal cost of public funds because it does not take into account the indirect effect of a higher labor tax on emissions and emissions tax revenue. This partial equilibrium concept is appropriate if the pollution sectors are infinitely small compared to the rest of the economy. This is indeed what the solution to the analytical model assumes (see next sub-section).

${ }^{14}$ The expressions for $\lambda$ and $\mu$ therefore do not distinguish between the supply elasticities of capital (the immobile factor) and labor (the mobile factor). Indeed, the elasticities of aggregate capital supply coincide with the corresponding labor supply elasticities.
} 
model, we assume that the upstream and downstream industries are small compared to the rest of the economy. This enables us to ignore effects on the real wage rate $W / P_{c}$ when solving for output and emissions in the upstream and downstream industries. ${ }^{15}$ We adopt $P_{c}$ as the numeraire.

\subsubsection{Upstream Industry}

Details of the solution are in the appendix. As indicated there, the demand for the upstream industry's output is given by

$$
x^{d}=-\varepsilon_{d}^{x}\left[p_{x}+\frac{\alpha_{e}^{y}}{\alpha_{x}^{y}} t_{e}\right]
$$

where $p_{x}+\frac{\alpha_{e}^{y}}{\alpha_{x}^{y}} t_{e}$ represents the relative change in the demand price of the output of the upstream industry (i.e., the price that the downstream industry has to pay for this input), and where $\alpha_{x}^{y} \equiv P_{x} X / P_{y} Y$ and $\alpha_{e}^{y} \equiv T_{e} E / P_{y} Y^{16}$ respectively stand for the intermediate good's cost share in the downstream industry and the emissions tax's cost share in that industry. The parameter $\varepsilon_{d}^{x} \geq 0$ denotes the (absolute value of) price elasticity of demand for the intermediate good. The appendix derives the determinants of this demand elasticity. ${ }^{17}$

The supply of the output of the upstream industry is given by

$$
x^{s}=\varepsilon_{s}^{x} p_{x}
$$

where the price elasticity of supply $\varepsilon_{s}^{x}$ depends on the intersectoral mobility of production factors (see the appendix). ${ }^{18}$

\footnotetext{
${ }^{15}$ We relax this assumption in the numerical model below. When computing aggregate welfare effects, the analytical model accounts for the impact of changes in net factor prices on taxed factor supplies. Although the relative changes in net factor prices and thus factor supplies are infinitesimal, they apply to a very large tax base (in comparison with the base of the environmental tax) and thus cannot be ignored when computing aggregate welfare effects.

${ }^{16}$ In the expressions below, the change in the tax rate $t_{e}$ always appears together with the cost share of the emission tax $\alpha_{e}^{y}$ as $\alpha_{e}^{y} t_{e}=\frac{E d T_{e}}{P_{y} Y}$. This product is thus well defined also if the initial emission tax, $T_{e}$, is zero.

${ }^{17}$ Specifically, a higher price of the intermediate good depresses the demand for the intermediate good through two channels: a negative substitution effect and a negative "scale" effect on the output of the downstream sector. The substitution effect depends on how easily the downstream industry can substitute capital for the polluting intermediate input in (4). The scale effect rises with the cost share of the intermediate input $\alpha_{x}^{y}$ and demand and supply elasticities of the final good $Y$ produced by the downstream industry.

${ }^{18}$ This elasticity becomes infinite if capital (i.e., the imperfectly mobile factor) does not play a role in
} 
Setting the demand for the upstream industry's output equal to its supply, we arrive at the following expressions for the emissions tax's impact on the upstream industry's output supply price

$$
p_{x}=-\left(\frac{\varepsilon_{d}^{x}}{\varepsilon_{d}^{x}+\varepsilon_{s}^{x}}\right) \frac{\alpha_{e}^{y}}{\alpha_{x}^{y}} t_{e},
$$

and its equilibrium output

$$
x=-\left(\frac{\varepsilon_{s}^{x} \varepsilon_{d}^{x}}{\varepsilon_{d}^{x}+\varepsilon_{s}^{x}}\right) \frac{\alpha_{e}^{y}}{\alpha_{x}^{y}} t_{e} .
$$

The emissions tax will not precipitate much of a decline in the supply price if $\varepsilon_{d}^{x}$ is small compared with $\varepsilon_{s}^{x}$. In this case, the demand price rises significantly and most of the tax burden falls on the demander of $X$, the downstream industry. Output of $X$ falls by a greater amount, the larger are the demand and supply elasticities.

\subsubsection{Downstream Industry}

The impact on the price of the output of the downstream industry is given by (see the appendix for the first equality; the second equality follows from (13))

$$
p_{y}=\frac{\varepsilon_{s}^{y}}{\varepsilon_{s}^{y}+\varepsilon_{d}^{y}}\left[\alpha_{x}^{y} p_{x}+\alpha_{e}^{y} t_{e}\right]=\left(\frac{\varepsilon_{s}^{x}}{\varepsilon_{d}^{x}+\varepsilon_{s}^{x}}\right)\left(\frac{\varepsilon_{s}^{y}}{\varepsilon_{s}^{y}+\varepsilon_{d}^{y}}\right) \alpha_{e}^{y} t_{e},
$$

where $\varepsilon_{s}^{y}$ and $\varepsilon_{d}^{y}$ represent the supply and (the absolute value of) the demand elasticity for the downstream industry (defined in the appendix). Demanders of the final output thus bear a large share of the burden of the environmental tax if supply is relatively elastic in both the upstream and downstream industries. In that case, a large share of the tax burden is shifted forward onto demanders.

The pollution tax's impact on emissions amounts to

$$
e=-\left[\left(\frac{\varepsilon_{s}^{x} \varepsilon_{d}^{x}}{\varepsilon_{d}^{x}+\varepsilon_{s}^{x}}\right) \frac{\alpha_{e}^{y}}{\alpha_{x}^{y}}+\sigma_{e} \frac{\alpha_{v}^{y}\left(1-\alpha_{k}^{y}\right)-\alpha_{x}^{y}-\alpha_{e}^{y}}{\alpha_{v}^{y}\left(1-\alpha_{k}^{y}\right)-\alpha_{x}^{y}}\right] t_{e},
$$

where $\sigma_{e}$ stands for the elasticity of substitution between $X$ and $g\left(C_{a} ; Y_{a}\right)$ in the emission function (5) and $\alpha_{k}^{y} \equiv R_{y} K_{y} /\left(R_{y} K_{y}+P_{x} X+T_{e} E+P_{c} C_{a}+P_{y} Y_{a}\right)$ and $\alpha_{v}^{y} \equiv\left(R_{y} K_{y}+\right.$ $\left.P_{x} X+T_{e} E+P_{c} C_{a}+P_{y} Y_{a}\right) / P_{y} Y=1-\left(W L_{y} / P_{y} Y\right)$. On the right-hand side of (16), the first term within the square brackets stands for the negative effect of a pollution

production of $Y$, if such capital is a perfect substitute for capital in the rest of the economy (i.e., the transformation curve (6) is linear), or if mobile labor is a perfect substitute for this capital in (1). In all these cases, the imperfectly mobile factor does not constrain production of the final good. 
tax on the output $X$ from the upstream industry (compare (14)). The second term in the square brackets captures the impact of end-of-pipe treatment. Inverting (16) yields the mapping between required pollution abatement $a(\equiv-e)$ and the pollution tax $t_{e}$. Applying this mapping, we obtain the following relationship between $\alpha_{e}^{y} t_{e}$, the required cost-increase (relative to the initial demand price of $X$ ), and the mandated reduction in emissions:

$$
\alpha_{e}^{y} t_{e}=\kappa a,
$$

where $\kappa \equiv 1 /\left[\left(\frac{\varepsilon_{s}^{x} \varepsilon_{d}^{x}}{\varepsilon_{d}^{x}+\varepsilon_{s}^{x}}\right) \frac{1}{\alpha_{x}^{y}}+\sigma_{e} \frac{\alpha_{v}^{y}\left(1-\alpha_{k}^{y}\right)-\alpha_{x}^{y}-\alpha_{e}^{y}}{\alpha_{e}^{y}\left[\alpha_{v}^{y}\left(1-\alpha_{k}^{y}\right)-\alpha_{x}^{y}\right]}\right]$. The left-hand side of the above equation represents the policy-induced increase in the cost of producing $Y$. The denominator in the definition of $\kappa$ incorporates the various channels through which emissions can be cut, namely: (i) abatement (which is the second term in the denominator), (ii) output of the final good (which is implicit in $\varepsilon_{d}^{x}$, see appendix), and (iii) input substitution between capital and the intermediate input in the downstream industry (also this is implicit in the definition of $\left.\varepsilon_{d}^{x}\right)$. The emission cost increase $\alpha_{e}^{y} t_{e}$ required to attain a certain emission cut falls as these three channels become more effective.

\subsection{Equity value neutrality}

We define a policy as achieving equity value neutrality (EVN) for an industry if it provides compensation just sufficient to offset what otherwise would be the loss of income for the imperfectly mobile factor (capital) employed in that industry. One indicator of required compensation is the share of potential revenues from a pollution tax or (auctioned) emissions permits that would need to be left with firms (foregone by the government) in order to achieve equity value neutrality.

\subsubsection{Gross potential revenues and compensation ratios}

The product $T_{e} E$ represents the gross potential revenues from pollution taxes. This is a gross concept because it does not net out any offsetting revenue loss due to an erosion of the labor or capital tax base. Let $t r^{g}$ refer to the change in gross potential revenues from an incremental change in the pollution tax (expressed relative to the initial output of the downstream industry $Y)$ :

$$
{ }_{t r}^{g} \equiv \frac{d\left(T_{e} E\right)}{P_{y} Y}=\alpha_{e}^{y}\left(t_{e}+e\right)=\left[\kappa-\alpha_{e}^{y}\right] a .
$$


Under competitive auctioning of pollution permits, the revenue from the auction equals the revenues obtained from a pollution tax that achieves the same pollution reduction. Thus an equivalent measure of the need for compensation is the share of potential revenues from an emissions permit program that must be left with firms rather than collected. This, in turn, is the same as the share of the permits that must be freely allocated (or grandfathered) to existing firms. We refer to this share as the gross compensation ratio. This ratio is in gross terms because we measure the compensation compared to the gross revenues, that is, prior to netting out any revenue losses from the erosion of distortionary tax bases. We begin by examining this ratio or share as applied to the upstream industry; we then consider the required ratio for the downstream industry.

Let $\theta_{x}^{g}$ represent the gross compensation ratio in the upstream industry. This share is given by (see appendix)

$$
\theta_{x}^{g}=\left(\frac{\varepsilon_{d}^{x}}{\varepsilon_{d}^{x}+\varepsilon_{s}^{x}}\right) /\left[1-\alpha_{e}^{y} / \kappa\right] .
$$

This expression indicates that $\theta_{x}^{g}$ is smaller, the larger the supply elasticity $\varepsilon_{s}^{x}$ or the smaller (in absolute value) the demand elasticity $\varepsilon_{d}^{x}$. The supply elasticity is large if immobile factors are relatively unimportant in that industry so that profits account only for a small share of the value of the industry's output in the initial equilibrium. In that case, not much compensation (relative to potential revenues) is needed. Expression (19) indicates also that the compensation ratio will be small if the environmental policy is not very stringent: small values of revenues from the emission tax, $\alpha_{e}^{y}$, imply low values for $\theta_{x}^{g}$. Intuitively, small levels for the share $\alpha_{e}^{y}$ imply that a more ambitious environmental policy yields substantial additional gross revenues because pollution abatement does not erode the base of the environmental tax much.

In some circumstances the gross compensation ratio $\theta_{x}^{g}$ can exceed unity. This occurs if initial environmental policy is stringent (i.e., if $\alpha_{e}^{y}$ is large) and supply elasticities are small compared to demand elasticities (i.e., if $\varepsilon_{s}^{x} / \varepsilon_{d}^{x}$ is small). Intuitively, an ambitious environmental policy yields relatively large abatement costs, while relatively small supply elasticities imply that producers bear a large fraction of these costs. If $\theta_{x}^{g}$ exceeds unity, freely allocating 100 percent of the permits (and enabling firms to retain 100 percent of the rents) is not sufficient to offset the gross loss of capital returns in $X$ producing firms. Under these circumstances, achieving equity value neutrality compels the government to provide further compensation. 
For the downstream industry the corresponding gross compensation ratio $\theta_{y}^{g}$ amounts to

$$
\theta_{y}^{g}=\left(\frac{\varepsilon_{s}^{x}}{\varepsilon_{d}^{x}+\varepsilon_{s}^{x}}\right)\left(\frac{\varepsilon_{d}^{y}}{\varepsilon_{s}^{y}+\varepsilon_{d}^{y}}\right) /\left[1-\alpha_{e}^{y} / \kappa\right] .
$$

This ratio will tend to be small if environmental policy is not ambitious or if supply is more inelastic in the upstream than in the downstream industry. For the first increment to abatement (that is, evaluating (20) when $\alpha_{e}^{y}=0$ ), the ease of end-of-pipe abatement (a larger value for $\sigma_{e}$ ) does not affect the compensation ratio. The reason is that easier end-of-pipe treatment reduces both the burden on downstream industry (the numerator) and the collected revenues (the denominator). However, for any further increments to abatement, ease of end-of-pipe treatment generally will have an effect on the compensation ratio $\theta_{y}^{g}$, although its direction is theoretically ambiguous. The ambiguity reflects the fact that $\sigma_{e}$ exerts two opposing effects on the potential revenues from the environmental policy. On the one hand, a higher $\sigma_{e}$ means that, to achieve a given reduction in emissions, the emissions tax rate (or permit price) has to rise less (implying a smaller value for $\kappa$ and thus $\alpha_{e}^{y} t_{e}$ ). This reduces potential revenues and thus raises the compensation ratio. On the other hand, because the emissions tax need not be so high, there is less erosion of the environmental tax base (the share $\alpha_{e}^{y}=T_{e} E / P_{y} Y$ declines). This exerts a positive impact on potential revenues and thus reduces the compensation ratio. At low, but non-marginal levels of abatement, the first effect dominates; at high levels of abatement, the second effect may (but does not necessarily) dominate.

\subsubsection{Net potential revenues and compensation ratios}

We can also compute the net potential revenues from the pollution tax. This net concept, $\operatorname{tr}^{n}$, takes account of the erosion of the bases of distortionary taxes on the production factors (see the appendix for the second equality):

$$
t r^{n} \equiv T q+\alpha_{e}^{y}\left(t_{e}(1-T)+e\right)=\alpha_{e}^{y}\left[t_{e}(1-T)+\lambda e\right]-\mu(1-T) \pi
$$

where $\pi$ is the required lump-sum compensation (before factor taxes) of the polluting industries to achieve equity value neutrality (again expressed relative to the initial output of the downstream industry $Y), q$ is the change in aggregate factor supply (expressed relative to the initial output of the downstream industry $Y$ ), and $T$ is the initial factor tax. The second equality assumes that the government employs the distortionary tax on labor and capital incomes, $T$, to balance the government budget. 
The net compensation ratio indicates the share of net potential permit or emissions tax revenue that must be devoted to compensation. It is a net concept for two reasons. First, potential revenue (the denominator of the ratio) is here defined as net of any revenue-losses stemming from the policy's adverse effect on the base of existing taxes, such as income or factor taxes. To the extent that the environmental policy reduces incomes, this tax base is reduced. In addition, the required compensation (the numerator) is net of any income taxes on such compensation. A net compensation ratio above 100 percent indicates that, after compensation, the environmental policy loses revenue. The net compensation ratio does not correspond to the share of permits that must be freely allocated to achieve equity value neutrality: that correspondence applies to the gross compensation ratio only.

The net compensation ratio is given by (see appendix): ${ }^{19}$

$$
\begin{gathered}
\left.\theta_{x}^{n}=\left(\frac{\varepsilon_{d}^{x}}{\varepsilon_{d}^{x}+\varepsilon_{s}^{x}}\right) /\left[1-\lambda \alpha_{e}^{y} /[\kappa(1-T)]-\mu\left(\frac{\varepsilon_{d}^{x}}{\varepsilon_{d}^{x}+\varepsilon_{s}^{x}}\right)\right)\right] \\
\left.\theta_{y}^{n}=\left(\frac{\varepsilon_{s}^{x}}{\varepsilon_{d}^{x}+\varepsilon_{s}^{x}}\right)\left(\frac{\varepsilon_{d}^{y}}{\varepsilon_{s}^{y}+\varepsilon_{d}^{y}}\right) /\left[1-\lambda \alpha_{e}^{y} /[\kappa(1-T)]-\mu\left(\frac{\varepsilon_{s}^{x}}{\varepsilon_{d}^{x}+\varepsilon_{s}^{x}}\right)\left(\frac{\varepsilon_{d}^{y}}{\varepsilon_{s}^{y}+\varepsilon_{d}^{y}}\right)\right)\right] .
\end{gathered}
$$

With positive initial factor taxes $T>0$ and a positive uncompensated wage elasticity of labor supply $\varepsilon_{u}$, the net ratios exceed the corresponding gross ratios. ${ }^{20}$ The reason is that the net compensation ratios account for the erosion of the base of the distortionary factor tax as a result of tighter environmental policy. Hence a larger share of the remaining tax revenue must be earmarked for compensation.

\subsubsection{Efficiency impacts}

We define the non-environmental welfare impact $\psi$ as the efficiency impact from the policy change, excluding the welfare effects from changes in environmental quality. This

\footnotetext{
${ }^{19}$ The compensation in the numerator of this ratio is computed net of the factor tax revenue that the government collects on the compensation. Hence, with $\pi$ denoting gross compensation, net compensation is computed as $(1-T) \pi$.

${ }^{20}$ The denominators in (22) and (23) are smaller than the denominators in (19) and (20) if $T, \varepsilon_{u}>0$. This is because $T, \varepsilon_{u}>0$ implies that $\lambda>1$ (see (9)) and $\mu>0$ (see (10)). In particular, the (in absolute value) larger second term in the denominators of (22) and (23) stands for the factor-tax-base erosion as a result of abatement costs associated with environmental policy. This term is relevant only if environmental policy yields first-order costs (i.e. if $T_{e}>0$ and thus $\alpha_{e}^{y}>0$ ). The third term represents the erosion of the factor tax base as a result of the required lump-sum compensation. This compensation is financed through higher distortionary taxes, which harm factor supply and thus erode the base of the factor $\operatorname{tax} T$.
} 
consists of the economy-wide changes in producer surplus, consumer surplus, and taxpayer surplus. The following equation (derived in the appendix) expresses $\psi$ as a function of $\pi$ (recall that $\pi$ represents the total amount of compensation to capital owners):

$$
\psi \equiv \frac{d U}{P_{y} Y \frac{\delta U}{\delta C}}=\lambda \alpha_{e}^{y} e-\mu \pi(1-T) .
$$

The above expression is general in that it applies for any value of compensation and does not depend on which industry's capital owners are compensated. In the particular case where compensation is provided to capital owners in both the upstream and downstream industries, and where the compensation is just sufficient to achieve equity value neutrality, the non-environmental welfare impact (expressed relative to required abatement) can be written as:

$$
\psi / a \equiv-\lambda \alpha_{e}^{y}-\mu(1-T)\left[1-\left(\frac{\varepsilon_{s}^{x}}{\varepsilon_{d}^{x}+\varepsilon_{s}^{x}}\right)\left(\frac{\varepsilon_{s}^{y}}{\varepsilon_{s}^{y}+\varepsilon_{d}^{y}}\right)\right] \kappa .
$$

The first term on the right-hand side of this expression stands for the non-environmental costs of the erosion of the base of both the environmental tax and the factor taxes. This cost exceeds the direct costs $\alpha_{e}^{y}$ (i.e. the erosion of the environmental tax) if the marginal cost of public funds exceeds unity (i.e., if $\varepsilon_{u} T>0$ so that $\lambda>1$ ). Intuitively, the government has to raise the distortionary tax $T$ to compensate the revenue loss resulting from the erosion of the base of this tax.

The second term on the right-hand side is the cost of providing lump-sum compensation to capital owners in the polluting industries. This additional cost is substantial if a large share of the environmental policy costs $\alpha_{e}^{y} t_{e}$ is borne by capital owners in these two industries rather than the consumers of the final good $Y$. This will be the case if production factors are particularly immobile (so that $\varepsilon_{s}^{x}$ and $\varepsilon_{s}^{y}$ are small) and $Y$ is a good substitute for $C$ in utility (so that $\varepsilon_{d}^{y}$ is large). The need to compensate capital owners implies that the government forgoes some of the revenue it could have obtained through auctioning of pollution permits. This would be an efficient source of revenue, since it is inframarginal. Instead, the government must depend more on ordinary distortionary taxes. As a result, the overall economic cost of a given environmental tax or quota policy is higher than it would be without the EVN requirement.

Let $\chi$ represent the ratio of the two terms at the right-hand sides of (24) and (25). This ratio is the additional efficiency cost of achieving equity value neutrality, relative to the marginal efficiency cost of achieving environmental improvement in the absence 
of the neutrality requirement. $\chi$ can be written as:

$$
\chi \equiv \frac{\mu \pi(1-T)}{\lambda \alpha_{e}^{y} a}=\varepsilon_{c} T \frac{\left[1-\left(\frac{\varepsilon_{s}^{x}}{\varepsilon_{d}^{x}+\varepsilon_{s}^{x}}\right)\left(\frac{\varepsilon_{s}^{y}}{\varepsilon_{s}^{y}+\varepsilon_{d}^{y}}\right)\right] \kappa}{\alpha_{e}^{y}},
$$

where we have used (9), (10), $\pi=\left[1-\left(\frac{\varepsilon_{s}^{x}}{\varepsilon_{d}^{x}+\varepsilon_{s}^{x}}\right)\left(\frac{\varepsilon_{s}^{y}}{\varepsilon_{s}^{y}+\varepsilon_{d}^{y}}\right)\right] \alpha_{e}^{y} t_{e}$, and (17).

The additional efficiency losses are substantial if distortionary taxes $T$ are large and compensated wage elasticities of labor supply are large. In that case, financing lumpsum subsidies to compensate capital owners is costly. The additional efficiency losses are also large if owners of capital in the pollution-associated industries cannot shift the tax burden onto consumers of the final good (i.e., if $\varepsilon_{s}^{x}$ and $\varepsilon_{s}^{y}$ are small compared to $\varepsilon_{d}^{x}$ and $\left.\varepsilon_{d}^{y}\right)$ so that sector-specific factors pay a large part of the burden of the emission tax. Another key factor is the parameter $\kappa$ : the larger the required cost increase $\alpha_{e}^{y} t_{e}$ (part of which must be compensated through lump-sum transfers) to arrive at a given emission cut $a$, the larger are the additional efficiency losses of establishing equity value neutrality.

Let the initial level of abatement refer to the amount of abatement from which one examines the cost of additional abatement. The abatement ratio $\chi$ is lower, the higher is this initial level or starting point. This is the case because higher initial abatement tends to imply a higher emission tax share $\alpha_{e}^{y} \equiv \frac{T_{e} E}{P_{y} Y}$. If the initial level of abatement is zero, the implicit emission tax rate is zero, i.e., $T_{e}=\alpha_{e}^{y}=0$. Starting from this initial level, the efficiency cost of lump-sum compensation is first-order, while the other element of efficiency cost - the economy-wide incremental cost of abatement (in terms of erosion of the environmental tax base) - is only second-order. ${ }^{21}$ Hence at low levels of initial abatement, the efficiency costs associated with distribution dominate the other (economy-wide) efficiency costs. Indeed, initially, $\chi$ is infinite. At higher initial levels of abatement, the marginal economy-wide costs are positive. As a function of the initial abatement level, these costs typically rise faster than the marginal costs of the needed lump-sum compensation. In contrast to the economy-wide marginal costs of abatement, the efficiency costs of compensation do not directly depend on the initial abatement level. Thus, as emissions-reductions become more extensive, the marginal

\footnotetext{
${ }^{21}$ To gain intuition for the second-order nature of the economy-wide efficiency cost, one might note that, in the regulated industry, the Harberger triangle associated with differences between private marginal cost and private marginal benefit (demand) vanishes as the level of abatement approaches zero. Even as abatement approaches zero, second-best "tax-interaction" and "revenue-recycling" effects can be "large." However, these second-best effects cancel out as abatement approaches zero (see, for example, Bovenberg and Goulder, 2002).
} 
costs of additional compensation become smaller compared to marginal economy-wide costs. At high levels of pollution abatement, pure efficiency costs of abatement, which are borne by the economy as a whole in terms of a smaller cut in factor taxes, tend to dominate the efficiency costs associated with redistribution.

As with its impact on the compensation ratios, the effect of ease of end-of-pipe treatment $\sigma_{e}$ on the additional efficiency cost of achieving equity value neutrality $\chi$ is ambiguous. Easier abatement reduces both the required compensation for the affected industries (and thus also the efficiency costs of establishing equity neutrality) and the economy-wide costs of abatement. At low, non-marginal levels of abatement (i.e., at low values for $\alpha_{e}^{y}$ ), the first effect tends to dominate but at higher levels the second effect may be stronger.

\subsubsection{A graphical illustration}

Figure 1 heuristically illustrates some of the main results from this section, with a focus on the downstream industry. Suppose that the government constrains emissions through pollution permits, and that all permits are auctioned. In this case the cost of producing $Y$ increases because the input $X$ effectively becomes more costly: the purchase of each unit of $X$ now requires also the purchase of permits for the emissions associated with $X$. Producers of $Y$ may mitigate this cost-increase through expenditures on endof-pipe treatment, which reduces the emissions associated with $X$, but the industry still faces an increase in cost because of required permit purchase and the cost of end-of-pipe treatment. Hence the industry's supply curve shifts up from $S_{0}$ to $S_{1}$. This implies a gross loss of producer surplus of cihd, which is the difference between original producer surplus (cie) and the post-policy producer surplus (dhe).

Now if instead the same number of permits are given out free rather than auctioned, producers receiving the permits will not have to pay the extra amount for each unit of $Y$ produced. Production up to $Q_{1}$ can be supplied according to the original supply curve $S_{0}$. However, production at the margin (that is, beyond $Q_{1}$ ) still requires the purchase of permits, and thus involves the extra cost. Hence beyond $Q_{1}$ the applicable supply curve is $S_{1}$. Thus the equilibrium output price is $a$, as in the case of auctioned permits. Recipients of free permits enjoy the benefits of a higher output price ( $a$ instead of $c$ ), yet they do not face the higher costs. These producers earn rents given by the area bfhe, which equals the rectangular area afhd when the marginal cost increase is

uniform across output. As drawn, these rents more than compensate for the gross loss 
of producer surplus.

The rectangle afhd represents what we have termed the gross potential revenues from the environmental policy. To achieve equity value neutrality, the government would need to leave firms with a large enough share of these potential revenues to offset the gross loss of producer surplus cihd. In the diagram, this share (or gross compensation ratio) is about 25 percent. The reader can confirm from the diagram that this share is larger, the greater (in absolute value) the elasticity of demand and the smaller the elasticity of supply for $Y$.

The ease of end-of-pipe treatment affects the magnitude of the rents and the compensation ratio. Easier end-of-pipe treatment implies that firms will rely more heavily on such treatment per unit of output. Firms' marginal costs of achieving emissions reductions will be lower, and thus for any given abatement target (or number of permits in circulation), the permit price will be lower. Hence the upward shift in the supply curve will be smaller than when end-of-pipe treatment is more costly. The smaller rise in the supply curve has two effects. First, it implies that the gross loss of producer surplus will not be so large, which diminishes the numerator of the compensation ratio. In addition, the smaller upward shift affects the potential revenues from the policy change. Depending on supply and demand elasticities, the potential revenues (represented by the rectangle afhd in the diagram) may be larger or smaller than in the case where end-of-pipe treatment is more costly. Thus, as discussed in connection with equation (20) above, the implication of end-of-pipe treatment for the compensation ratio is theoretically ambiguous.

\section{A Numerical Model}

Here we develop and apply a numerical model in order to obtain quantitative results and consider the impacts of large policy changes.

\section{$3.1 \quad$ Structure}

We briefly describe the model here; a complete description is in a technical appendix, available from www.stanford.edu/ goulder/BGGNumericalDoc-Web.pdf. The formal structure of the numerical model and its degree of aggregation match that of the analytical model described in the previous section. However, this model relaxes the 
assumption that the industries $X$ and $Y$ are "small," thus allowing the real wage to be endogenous. Moreover, since the model is solved numerically, its solution does not rely on linearization techniques. Hence this model can consider general equilibrium impacts and large policy changes.

The model adopts constant-elasticity-of-substitution (CES) functional forms for the production functions of the intermediate input $X$ and the final goods $Y$ and $C$. As in the analytical model, each industry employs labor and capital as inputs, and industry $Y$ employs the intermediate input $X$ as well (with the same nesting as in the analytical model). Thus the production function for the $Y$ industry is given by

$$
Y=\gamma_{Y}\left[\alpha_{y v} v^{\frac{\sigma_{y}-1}{\sigma_{y}}}+\left(1-\alpha_{y v}\right) L_{y}^{\frac{\sigma_{y}-1}{\sigma_{y}}}\right]^{\frac{\sigma_{y}}{\sigma_{y}-1}}
$$

with

$$
v=\gamma_{v}\left[\alpha_{v} K_{y}^{\frac{\sigma_{v}-1}{\sigma_{v}}}+\left(1-\alpha_{v}\right) X^{\frac{\sigma_{v}-1}{\sigma_{v}}}\right]^{\frac{\sigma_{v}}{\sigma_{v}-1}} .
$$

To capture the imperfect mobility of capital across industries, we apply a CES capital transformation function:

$$
K=\gamma_{k}\left[\alpha_{k} K_{x}^{\frac{\sigma_{k}-1}{\sigma_{k}}}+\beta_{k} K_{y}^{\frac{\sigma_{k}-1}{\sigma_{k}}}+\left(1-\alpha_{k}-\beta_{k}\right) K_{c}^{\frac{\sigma_{k}-1}{\sigma_{k}}}\right]^{\frac{\sigma_{k}}{\sigma_{k}-1}},
$$

where $K$ represents the aggregate capital stock. The parameter $\sigma_{k}$ controls the curvature of this function. We employ negative values for $\sigma_{k}$ so that the transformation function is bowed out from the origin. Successive increments to the supply of any given type of capital thus require ever-larger sacrifices of other types of capital, in keeping with increasing marginal adjustment costs. In contrast to capital, labor is perfectly mobile across industries.

The household utility function is CES:

$$
U=\left(\alpha_{g} G^{\frac{\sigma_{u}-1}{\sigma_{u}}}+\alpha_{h} H^{\frac{\sigma_{u}-1}{\sigma_{u}}}\right)^{\frac{\sigma_{u}}{\sigma_{u}-1}},
$$

where $G$ is a CES composite of the final goods $Y$ and $C$ :

$$
G=\left(\alpha_{h c} C^{\frac{\sigma_{g}-1}{\sigma_{g}}}+\alpha_{g y} Y^{\frac{\sigma_{g}-1}{\sigma_{g}}}\right)^{\frac{\sigma_{g}}{\sigma_{g}-1}},
$$

and $H$ is a CES composite of labor supply and aggregate capital supply:

$$
H=\left(\alpha_{h l}(\bar{L}-L)^{\frac{\sigma_{h}-1}{\sigma_{h}}}+\alpha_{h k}(\bar{K}-K)^{\frac{\sigma_{h}-1}{\sigma_{h}}}\right)^{\frac{\sigma_{h}}{\sigma_{h}-1}}
$$


and where $\bar{L}$ and $\bar{K}$ represent the maximum potential labor supply (endowment of labor time) and capital supply, respectively.

We adopt the following emissions function:

$$
\frac{E}{X}=\gamma_{e}\left[1+\beta_{e}\left(\frac{G_{a}}{X}\right)^{\rho_{e}}\right]^{\frac{-1}{\rho e}} \beta_{e}>0 ; \quad 0<\rho_{e}<1
$$

where end-of-pipe abatement $G_{a}$ is a CES composite of the two final goods $C$ and $Y$, with the same parameters as in (31).

The emission function $E / X$ can be represented as $\gamma_{e} f\left(G_{a} / X\right)$. The function $f($. features the following desirable properties:

- $f^{\prime}(0) \Rightarrow-\infty$. This first unit of end-of-pipe treatment is very productive in cutting emissions. Accordingly, end-of-pipe treatment is positive if emissions are constrained (implying a positive shadow price of pollution permits)

- $f(\infty)=0$. Pollution is eliminated completely if end-of-pipe treatment is very large.

- $f(0)=1$. Without any end-of-pipe treatment, pollution remains finite.

\subsection{Equilibrium}

The requirements of the general equilibrium are that (1) household supply of labor must equal aggregate labor demand by firms, (2) demand for capital by each industry $i$ $(i=x, y, c)$ must equal the quantity supplied to that industry, (3) pollution emissions must equal the pollution level stipulated by environmental policy, and (4) government revenue must equal real transfers to households.

The nominal price of labor is the numeraire. The primary prices in the model (from which all other prices can be determined) are the rental prices of capital $\left(R_{k_{i}}\right.$, $i=x, y, c)$, the price of pollution permits, and the tax on factor income. ${ }^{22}$ To obtain the general equilibrium, the model identifies the vector of primary prices that meet the

\footnotetext{
${ }^{22}$ As indicated in the next subsection, in some policy experiments we require that real government revenue (and transfers) remain constant. Under these policies, we adjust marginal factor tax rates to offset any new revenue resulting from the introduction of pollution taxes. In other policy experiments, we do not offset the increase in government revenue from environmental taxes. Under these policies government budget balance is achieved through increases in transfers that match the increase in government revenue.
} 
four requirements above. Walras's law implies that the labor market clears when the all other markets clear.

Some experiments add the requirement of equity value neutrality for the downstream industry, the upstream industry, or both. In these cases we require, for the industry or industries involved, that the number of freely allocated permits be just sufficient to prevent a loss of profit rates for the owners of the initial (i.e., pre-policy-change) capital stock. The extent of grandfathering affects the revenue yield from the policy and thus the extent of revenue recycling. Hence, when we impose the equity value neutrality requirement, the solution algorithm solves simultaneously for primary prices and the required extent of grandfathering.

\subsection{Data}

The numerical model is applied to the U.S. We choose the electricity industry as the downstream industry and regard the suppliers of fossil fuels to this industry as the upstream industry. We focus on control of sulfur dioxide $\left(\mathrm{SO}_{2}\right)$ emissions.

Table 1 indicates the inter-industry flows in our data set. These flows derive from the U.S. Commerce Department Bureau of Economic Analysis's Benchmark Input \& Output Tables for 1992. The emissions data come from the 1992 column of Table 12.6 of the Energy Information Agency's Annual Energy Review 1999.

Table 2 indicates the parameters used in the model. The elasticities of substitution in production are taken from the disaggregated general equilibrium data set developed by Barreto, Gurney, Xie, and Goulder (2002). For the $Y$ industry, we calibrate the model to generate production and abatement elasticities consistent with those from the detailed "HAIKU" model of the U.S. electricity industry developed at Resources for the Future. The substitution elasticities $\sigma_{y}$ and $\sigma_{v}$ imply that, compared to capital, labor is a much better substitute for $X$.

The capital adjustment parameter $\sigma_{k}$ is chosen so as to yield capital responses roughly consistent with findings from a recent survey by Chirinko, Fazzari, and Meyer (2002) indicating that the elasticity of investment with respect to the cost of capital is in the range of .25-.4.

We calibrate the model to generate uncompensated and compensated labor supply elasticities of 0.15 and 0.4 , respectively. ${ }^{23}$ This is consistent with the survey by Russek

\footnotetext{
${ }^{23}$ To calibrate the model to these labor supply parameters, we numerically solve the household's utility maximization problem with given prices and observe the change in labor supply resulting from a change
} 
(1996). Together, these two elasticity targets yield the values for the elasticity of substitution between leisure and capital and the benchmark ratio of total (labor plus leisure) time to labor time. These values imply a marginal excess burden of 0.24 for labor taxes. As in the analytical model, capital supply elasticities are set equal to labor supply elasticities. With the same factor tax rate on both capital and labor income, the marginal excess burden for capital taxes is thus the same as that for labor taxes.

\subsection{Policy Experiments and Results}

We employ the model to explore how much compensation is required to achieve equity value neutrality (EVN) and the efficiency costs of providing such compensation. Under the assumptions of the numerical model (including, in particular, the absence of uncertainty), for any policy involving pollution permits there is an equivalent policy involving a pollution tax. For example, a policy involving 100 percent auctioning of pollution permits is equivalent to a pollution tax without any inframarginal exemption and whose tax rate equals the permit price. Similarly, a policy involving partial free allocation of permits can be made equivalent to a pollution tax with a partial inframarginal exemption and with a tax rate equal to the permit price. ${ }^{24}$ In the following, we describe all the policy experiments as permits policies, although the results apply also to tax policies generating the same emissions-reductions.

\subsubsection{Results under Central Values for Parameters}

We conduct five policy experiments; these are summarized in Table 3. Under each of the five policies, we vary the stringency of the environmental regulation so that the cuts in $\mathrm{SO}_{2}$ emissions range from 0 to 75 percent of initial, unregulated emissions.

Policies 1 and 2 involve 100 percent auctioning of pollution permits to industry $Y$. These two policies differ in the ways that the net revenues from the policy are returned to the private sector to preserve the government's budget balance. Under Policy 1, the net revenues are returned as lump-sum transfers to households. Under Policy 2, they are recycled through cuts in the marginal rates of labor and capital taxes. The rate

in the after-tax wage. We solve this as a constrained optimization problem, where the amount of capital supplied is fixed. To calculate the compensated elasticity, we also alter the household's income so that utility remains unchanged despite the the change in the after-tax wage.

${ }^{24}$ For a further discussion of equivalences between pollution permit and tax policies, see Farrow (1999) and Williams (2002). 
cuts are the same for labor and capital and apply to all uses of these factors. ${ }^{25}$

Policies 3-5 are like Policy 2 in attaining government budget balance through adjustments in the marginal rates of factor taxes. However, in contrast to Policy 2, these policies impose the EVN requirement in at least one of the pollution-related industries. EVN is achieved through the free allocation of a share of the permits to the industry in question. The permits are grandfathered on the basis of the capital stock in the industry before the environmental policy is announced and implemented. Only the owners of existing capital are compensated: capital that moves into the industry afterwards does not benefit from grandfathering. Policy 3 involves free allocation of enough permits to bring about EVN in the downstream industry. Policy 4 attains EVN in the upstream industry. Policy 5 achieves EVN in both pollution-related industries.

Free permit allocation implies a sacrifice of potential revenue. Thus, for any given pollution reduction, the reduction in factor tax rates will generally be less extensive under policies 3-5 than under Policy 2. As indicated by the analytical model, this is a main source of the cost of achieving EVN.

Policies 1 and 2: Table 4 displays the equilibrium outcomes under each of the policies. First consider policies 1 and 2. Permit prices and potential permit revenues rise with the extent of the required pollution reduction. Thus, for the pollution cuts we are considering here, the Laffer curve for permit revenues is still rising. The need to purchase permits and to abate pollution increases production costs in industry $Y$, leading to higher output prices and lower equilibrium output. This is accompanied by a reduced use of factors in this industry and lower rental rates on capital. Even though capital is imperfectly mobile and sector-specific rental rates fall substantially, sector $Y$ reduces demand for capital more than demand for labor. The reason is that capital is complementary to the polluting intermediate input $X$. Hence labor rather than capital substitutes for the more expensive intermediate input $X$.

Reduced output and input substitution in industry $Y$ curtails demand for the output $X$ of the upstream industry, which in turn causes prices, profits, and factor use to fall in that industry as well. In this sector, labor use declines more than capital demand because, in contrast to capital, labor is perfectly mobile intersectorally.

\footnotetext{
${ }^{25}$ Recycling through marginal rate cuts implies smaller efficiency losses, so long as the tax that is cut has a positive excess burden. This efficiency benefit has been termed the "weak double dividend" from recycling environmental tax revenues in this way. See Goulder (1995).
} 
Higher prices for the output of the downstream industry cause a shift in demand toward industry $C$, the other final good industry. The impacts on industry $C$ are relatively small, however. The use of capital in this industry rises because profit rates in this industry are much less significantly reduced than in the pollution-related industries. Figure 2 shows the efficiency impact of these two policies. This impact is measured by the equivalent variation, which is expressed as a percentage of benchmark income (see also the bottom rows of Table 4). Efficiency costs rise more than in proportion to the extent of pollution reduction. Table 4 reveals that if pollution cuts are modest (e.g., 10 percent, the efficiency costs of Policy 2 are less than half that of Policy 1. However, the ratio of Policy 2 to Policy 1's efficiency costs rises with additional pollution abatement. Indeed, with large pollution cuts, the regulated industry's abatement costs become large and differences in revenue-recycling methods become relatively less important to the overall efficiency costs. ${ }^{26}$

Policy's 2 relative advantage in terms of efficiency manifests itself primarily in industry $C$. Much of the household's higher (relative to policy 1) real income is devoted to increased purchases of output from this industry. Moreover, this sector benefits from the boost in aggregate factor supply produced by lower factor tax rates (compared to Policy 1).

Policies 3-5: These policies differ from Policy 2 in that they involve the free allocation of enough pollution permits to achieve EVN. Figure 3 shows the additional efficiency cost implied by the EVN requirement (under policies 3-5), as a percentage of the efficiency cost under Policy 2. These additional costs are closely related to the variable $\chi$, introduced in Section 2. The only difference is that Figure 3 provides the additional costs of EVN of the entire amount of abatement (compared to no abatement at all), while $\chi$ represents the additional costs under EVN for a marginal increment to abatement (measured compared to the marginal efficiency costs under policy 2).

\footnotetext{
${ }^{26}$ The potential revenues from emissions permits are the product of the number of permits issued (or allowable pollution) and the permit price. More extensive abatement obviously implies fewer permits issued. In our simulations, the increase in permit prices offsets the reduction in the number of permits and allows potential revenues to rise, but this increase is only modest compared to the rise in abatement costs. Thus, as abatement becomes extensive it makes relatively little difference whether permit revenue is recycled in a lump-sum fashion or by way of cuts in marginal tax rates. Similar results were obtained in Goulder et al. (1997). This study showed that the difference between recycling revenues lump-sum and recycling them through marginal tax cuts vanishes as pollution abatement approaches 100 percent.
} 
Under all policies, the relative increase in efficiency cost declines with the extent of abatement. If the required abatement is below 5 percent, achieving EVN for the downstream industry (Policy 3) raises costs by over 100 percent, and achieving EVN for the upstream industry (Policy 4) raises costs by about 75 percent. In contrast, when required emissions reductions exceed 50 percent, the relative increase in cost under the two policies is below 18 and 12 percent, respectively. The costs under Policy 5 are very close to the sum of the costs under policies 3 and 4, so that the relationship between the relative cost increase and the stringency of the environmental policy follows a similar pattern.

These results square with the findings of the analytical model. Let "ordinary efficiency costs" refer to the efficiency costs under Policy 2, that is, in the absence of an EVN constraint. The analytical model indicated that, starting from an equilibrium without abatement, the first incremental amount of abatement implies no first-order ordinary efficiency costs. In contrast, achieving EVN involves first-order efficiency costs, even at the first increment of abatement. Thus the additional efficiency cost of preventing adverse redistributional effects under policies 3, 4 and 5 (relative to the marginal efficiency costs under Policy 2) is infinite for the first increment to abatement. This ratio then falls with abatement, since the redistributional effects (and thus the required compensation for the affected industries) grow more slowly than the economy-wide efficiency costs. Indeed, at higher amounts of abatement, the economy-wide costs become increasingly important relative to the costs that the environmental policies impose on the regulated industries.

Figures $4 \mathrm{a}$ and $4 \mathrm{~b}$ display respectively the average and marginal compensation ratios for the downstream industry under Policy 3. The average compensation ratios are total required compensation divided by total revenue collected. Thus they apply to "large" amounts of abatement (compared to a situation without any abatement) and differ from the marginal compensation ratios applying to incremental increases in abatement, which were computed in Section 2. In each figure, the compensation ratios are calculated on a gross and net basis. As discussed in Section 2, the difference between the gross and net ratios is that the net ratio includes the impact on the factor tax base and computes compensation net of the factor tax revenue collected on that compensation.

The figures conform to the analytical results in showing that net compensation ratios exceed the gross compensation ratios. This is the case for both average and marginal compensation ratios. They also support the analytical results in revealing that the compensation ratios rise with the extent of abatement, and that the marginal and av- 
erage net compensation ratios can exceed 100 percent. In particular, under Policy 3 the average net compensation ratio rises above 100 percent once required abatement exceeds about 73 percent. At abatement levels beyond this level, the gross revenue from auctioning (some of) the permits is less than the policy-induced loss of revenue from existing taxes stemming from the erosion of the factor tax base. At these abatement levels, the government loses net revenue from imposing EVN. Despite the auctioning of some of the permits ${ }^{27}$, preserving the government's budget balance requires an increase in factor tax rates.

These results offer some perspectives on current policy initiatives. The Bush Administration's Clear Skies Initiative, in particular, would introduce tradable pollution permits to control emissions of sulfur dioxide $\left(\mathrm{SO}_{2}\right)$, mercury, and nitrogen oxides from electric power plants in the U.S. The Initiative would require $\mathrm{SO}_{2}$ reductions of 70 percent from the existing emissions cap (and by a larger percentage relative to the emissions levels that would apply in the absence of any controls). Effectively, 80 percent of the $\mathrm{SO}_{2}$ permits would be freely allocated to the utilities. ${ }^{28}$ Results from our numerical model, in Figure 4a, suggest that a smaller percentage - about 50 percent — of the permits would need to be freely allocated to compensate the industry. This implication should be interpreted with caution: a more detailed model would be needed to calculate the compensation ratio with greater precision. Particularly significant is the fact that our model abstracts from heterogeneity among firms within each industry. For example, it does not distinguish older coal-fired generators (responsible for most of the $\mathrm{SO}_{2}$ emissions) from newer natural-gas-fired power plants. The presence of intra-industry heterogeneity might or might not imply higher compensation ratios, depending on how equity value neutrality is defined and whether the government can observe heterogeneity and finely target compensation. ${ }^{29}$

\footnotetext{
${ }^{27}$ That some of the permits are auctioned is indicated by the fact that the gross compensation ratio is positive.

${ }^{28}$ More precisely, the Initiative would freely allocate 99 percent of the permits initially, reduce this percentage by 1 percentage point each year for 20 years, and then reduce it by 2.5 percent each year for 32 years, at which point all permits would be auctioned. Approximately 80 percent of the discounted potential revenues over this 52-year interval would be foregone through the free allocation of permits.

${ }^{29}$ The compensation ratios calculated in the numerical model are consistent with those in a heterogeneous setting if the government defines EVN as the requirement that average losses in the targeted industry must be zero. They would also be consistent with the situation where the government had sufficient flexibility to achieve EVN for each firm individually, tailoring compensation to the specific features of individual firms, and removing any profit-increases from firms that would otherwise experience such increases from the policy. In contrast, if the government insisted that no firm suffer a
} 
Figures 5a and 5b provide for Policy 4 (involving compensation to the upstream industry) the same sorts of information as that provided by figures $4 \mathrm{a}$ and $4 \mathrm{~b}$ for Policy 3. The ratios for the upstream industry (under Policy 4) follow a similar pattern to those for the downstream industry (under Policy 3). However, the ratios in that industry are somewhat lower (for given levels of abatement). This is because elasticities of supply are higher for industry $X$ than for industry $Y{ }^{30}$

These experiments bring out several key findings. First, they clarify how the efficiency costs of EVN change with the amount of abatement. In absolute terms, the cost implied by introducing the EVN constraint rises with the extent of abatement. At the same time, relative to the cost in the absence of the EVN constraint, the cost from the EVN constraint falls as abatement becomes more extensive.

Second, the experiments reveal significant differences between gross and net compensation ratios, especially at high abatement levels. These differences reflect the erosion of the tax base resulting from the environmental policy's impact on factor incomes. The erosion of the factor tax base - a phenomenon emphasized in recent numerical experiments by Smith, Ross, and Montgomery (2002) - becomes quite large when environmental policy is fairly stringent. With greater erosion of the tax base, the net revenue collected from environmental taxes or auctioning of emissions permits is lower, so that the cuts in pre-existing taxes financed by the environmental policy must be more modest. Indeed, in our central-case experiments the net compensation ratio under Policy 3 exceeds 100 percent when abatement approaches 75 percent. At these levels of abatement, environmental policy collects no net revenue if the harmed industries must loss, but lacked sufficient instruments to compensate each and every firm exactly, some firms would be overcompensated. In this case, the average compensation ratio for the industry would be higher than that predicted by the numerical model.

The significance of heterogeneity to compensation ratios has been explored in detail by Burtraw et al. (2002). That study, which does not focus on the efficiency cost of compensation, calculates compensation ratios for $\mathrm{CO}_{2}$ emissions permits programs applied to the electric utilities industry, taking account of the heterogeneity among electric power generators.

${ }^{30}$ We have performed separate experiments applicable to $\mathrm{CO}_{2}$ policy, similar to those in Bovenberg and Goulder (2001). These experiments calculate the compensation ratio applicable to upstream (fossil fuel supplying) industries under a policy involving a 22 percent reduction in $\mathrm{CO}_{2}$ emissions. In the present model, the compensation ratio is 16.2 percent. This compares with a ratio of 11 percent in Bovenberg and Goulder (2001). It is difficult to pinpoint the sources of differences in the results, since the models differ in several ways. However, one potential factor is that the present model assumes somewhat higher demand elasticities than in the earlier study. This could partly account for the higher compensation ratios. 
be compensated; to preserve budget-balance, the government must raise existing factor

taxes. Tax-base erosion adds to the cost of revenue-neutral environmental reforms by limiting the government's potential to reduce pre-existing distortionary taxes.

Finally, we find that even though the policies we consider target $\mathrm{SO}_{2}$ emissions from the downstream (electric utilities) industry, owners of capital in the upstream (fossil fuel) industry bear a significant share of the overall burden to capital owners. As indicated in Figure 3, the added efficiency cost of achieving EVN under Policy 4 is about two thirds the added cost under Policy 3. This extra cost is proportional to the compensation required or revenue-sacrifice involved. Hence the burden to owners of upstream industry capital is approximately two thirds the size of the burden to owners of capital in the downstream industry.

\subsubsection{Sensitivity Analysis}

We now consider the sensitivity of results to alternative values for key parameters.

End-of-pipe treatment. One distinguishing feature of the present study is its consideration of end-of-pipe treatment as one of the channels through which firms can reduce their pollution emissions. The ease of such treatment is governed by the parameter $\beta_{e}$, whose central case value is 2 . The low case employs a value of .01 (implying virtually no possibility of end-of-pipe treatment) and the high case a value of 4 .

Figure 6a shows, for Policy 3, the gross and net (average) compensation ratios, for low and high values of $\beta_{e}$. The impact on the compensation ratios is minor. This squares with the analytical model, which showed easier abatement impacts the compensation ratios through two offsetting effects. On the one hand, easier abatement reduces the potential revenues from emission cuts as lower emission tax rates are required. On the other hand, with easier abatement, lower implicit tax rates are required, thereby reducing the erosion of the tax base and raising potential revenues. These diverging impacts on potential revenues exert offsetting effects on the compensation ratios. The ease of endof-pipe treatment also has relatively little effect on the added cost of Policy 3's EVN constraint, relative to the cost under Policy 2. This is shown in Figure 6b. Consistent with the analytical results, at low levels of abatement, easier abatement reduces the compensation ratio as the burden on the affected industry is smaller and thus less compensation is required. At higher levels of abatement, easier abatement substantially reduces the economy-wide costs of emission reductions in terms of an erosion of the environmental tax base and this impact on the denominator of $\chi$ dominates the impact 
on the numerator (i.e., the efficiency costs of the required compensation).

Although the ease of end-of-pipe treatment exerts only little impact on Policy 3's compensation ratios or its relative increment to efficiency costs (compared with Policy 2 ), it substantially affects the absolute cost of achieving emissions reductions. This is revealed by Table 5 , which contains the implications of alternative values of $\beta_{e}$ and other parameters for the costs of achieving emissions reductions under Policy 2. The numbers in the table are the ratio of efficiency costs under alternative parameters to efficiency costs in the central case. More possibilities for end-of-pipe treatment significantly reduce the costs of emission cuts.

Input substitution. Figures $7 \mathrm{a}$ and $7 \mathrm{~b}$ show for Policy 3 the implications of alternative values for $\sigma_{y}$, the elasticity of substitution between $L$ and $v$ (a composite of $X$ and $K$ ) in the production of $Y$. The central case value for $\sigma_{y}$ is 0.75 . Here we halve and double this elasticity. In keeping with the analysis of Section 2 (which considered increases in $\varepsilon_{d}^{x}$ and $\varepsilon_{d}^{y}$ ), Figure 7a shows that a higher value of $\sigma_{y}$ raises the compensation ratios. A larger $\sigma_{y}$ implies that a larger share if the emission cut comes from substitution away from $X$ and $K$, as opposed to end-of-pipe treatment. This implies a greater reduction in the demand for capital and a larger reduction in profits in industry $Y$. Also in the upstream sector, demand for capital declines as a result of lower demand for $X$. Thus the required compensation is higher.

Figures $8 \mathrm{a}$ and $8 \mathrm{~b}$ provide results for different values of $\sigma_{v}$, the elasticity of substitution between $K$ and $X$ in the production of the composite input $v$ in the $Y$ industry. The implications of a higher $\sigma_{v}$ for the capital owners in the downstream sector are different from a higher $\sigma_{y}$. A higher elasticity $\sigma_{v}$ benefits capitalists in sector $Y$ because it is easier to substitute capital for the dirty input, which protects after-tax profits in that sector. In contrast, owners of upstream-industry capital suffer from a higher elasticity as the demand for $X$ declines more substantially. Just as in the previous case, higher substitution elasticities mitigate the efficiency costs of abatement (see Table 5).

Substitution in Household Utility. Figures 9a and 9b consider different values for $\sigma_{g}$, the elasticity of substitution between $C$ and $Y$ in the $G$ subutility function. Here we halve and double this elasticity, whose central case value is 0.9 . When this elasticity is high, the demand for $Y$ is more elastic. As indicated in Section 2, this means that capital will bear a larger share of the burden of the pollution regulation. Hence the compensation ratio is higher. This elasticity is a significant issue in the context of the tradable emissions permits system which is now being planned for the European Union. European manufacturers of carbon-intensive products argue that the permits system will 
cause them to lose considerable share of the market to foreign (that is, non-European) firms. Thus they fear that the elasticity of demand for their goods is fairly high. These results suggest that a highly elastic demand would imply a high compensation ratio. A higher $\sigma_{g}$ raises the added cost of compensation under Policy 3 relative to Policy 2 (Figure 9b) through two channels: raising the required compensation and lowering the economy-wide efficiency costs of pollution abatement (see also Table 5).

Figures 10a and 10b compare different values for $\sigma_{u}$, the elasticity between the $G$ and $H$ composites in utility. This elasticity determines the elasticity of factor supplies and thus the erosion of the factor tax base. As discussed in Section 2, the greater the erosion of the factor tax base, the wider the gap between the gross and net compensation ratios. Thus, in Figure 10a, a higher $\sigma_{u}$ raises the gap between the gross and net ratios. The analytical model revealed that higher labor supply elasticities raise the additional efficiency losses of EVN, $\chi$. Figure 10b confirms this result. At the same time, a higher $\sigma_{u}$ implies greater flexibility in the economy, so the overall efficiency costs of achieving given levels of abatement under Policy 2 are smaller (Table 5).

Figures $11 \mathrm{a}$ and $11 \mathrm{~b}$ relate the gross compensation ratios and efficiency costs to $\sigma_{k}$, which controls the ease of capital adjustment across industries. The central case value for $\sigma_{k}$ is -1 . We consider alternative values of -0.5 and -2.0 , respectively, for $\sigma_{k}$. When $\sigma_{k}$ is low in absolute value, capital is relatively inelastic and thus bears a larger share of the burden of the environmental regulation. Hence the required compensation is larger. By increasing the required compensation, a low value of $\sigma_{k}$ also raises the relative efficiency costs of Policy 3 (Figure 11b).

\section{Conclusions}

A politically realistic approach to environmental policy requires consideration of distributional impacts. It seems important to consider, in particular, how to mitigate or avoid potentially adverse impacts on groups with effective veto power. Representatives of pollution-related industries seem to be one such group. In this paper we have considered the efficiency costs of achieving equity value (that is, preventing profit-losses) in pollution-related industries.

Losses of profit can be avoided through the free allocation of emissions permits or, equivalently, the exemption of inframarginal emissions from a pollution tax. However, such policies increase efficiency costs because they compel the government to forego potential pollution-tax or pollution-permit revenue and rely more heavily on ordinary 
distortionary taxes. Our paper employs analytically and numerically solved models to examine the efficiency costs implied by these compensation measures.

The added efficiency cost is related to the compensation ratio: the share of potential pollution-permit or pollution-tax revenue that the government must forego to protect the industries in question. We explore what determines the magnitude of this ratio in both upstream and downstream industries, and how these ratios are related to efficiency costs.

The analytical model shows that, in the upstream industry, the gross compensation ratio increases to the extent that profits account for a large share of the industry's output, capital supply is inelastic (mobility is limited), or demand for output is rather elastic. For the downstream industry, this ratio rises to the extent that capital is more immobile than in the upstream industry and output demand is highly elastic. In both industries, the ratio rises with the stringency of environmental policy (the extent of required abatement). These results are reinforced by numerical simulations. The gross compensation ratio corresponds to the share of emissions permits that must be freely allocated to prevent a loss of profit. Our numerical simulations suggest that the Bush Administration's Clear Skies Initiative would overcompensate electric utilities by freely allocating more than the share required to preserve their profits.

The two models also indicate that, in absolute terms, the added cost implied by introducing the EVN constraint rises with the extent of abatement. At the same time, relative to the cost in the absence of the EVN constraint, the added cost from the EVN constraint falls as environmental policy becomes more stringent. With more abatement, the cost of neutralizing adverse profit-impacts shrinks relative to the other efficiency costs related to the policy intervention.

The simulations reveal the significance of erosion of the factor tax base, especially at high abatement levels. As the amount of abatement becomes large, the erosion of the tax base can imply high net compensation ratios. Indeed, in our central-case experiments the net compensation ratio under Policy 3 exceeds 100 percent when abatement approaches 75 percent. At these levels of abatement, this environmental policy collects no net revenue; to preserve budget-balance, the government needs to raise existing factor taxes.

Some caveats are in order. First, while preventing profit losses might well increase the prospects for political acceptability of various policies, it does not guarantee it. The political process is complex, and depends on more than this particular distributional issue. A second and closely related issue is that we have concentrated entirely on 
compensation to a single immobile factor, which in the numerical model is calibrated to be existing capital. One might wish to consider the costs of compensating other important stakeholders. Offering compensation to workers for temporary or long-term unemployment seems especially worthy of consideration. ${ }^{31}$ Third, our models are fairly simple. They have the attraction of transparency and flexibility, but more detailed models could yield more precise quantitative results. Finally, we have not considered the full range of potential environmental policies or compensation mechanisms. In future work we plan to examine the costs of compensation under other policies, such as technology mandates and performance standards. In addition, we would like to explore other compensation instruments, such as sector specific cuts in capital or labor taxes. Some of these alternative instruments might well be more efficient mechanisms for spreading more evenly the burden of environmental policy initiatives.

\footnotetext{
${ }^{31}$ If the policy involves gross costs in the aggregate, then (ignoring the environmental benefits) clearly it is not possible to compensate every affected party. Overcoming political obstacles may nevertheless be possible, so long as the especially influential stakeholders are compensated or otherwise brought on board. Our paper is motivated by the viewpoint that certain energy-related industries have had and will continue to have a particularly significant impact on environmental policy outcomes in the U.S.
} 


\section{References}

Anderson, Soren, and Richard Newell, 2003. "Prospects for Carbon Capture and Storage Technologies." Discussion Paper 02-68, Resources for the Future, Washington, DC.

Barreto, Daniel, Derek J. Gurney, Xiaoying Xie, and Lawrence H. Goulder, 2002. "An Intertemporal General Equilibrium Model for Analyzing U.S. Energy and Environmental Policies: Data Documentation." Working paper, Stanford University.

Banzhaf, Spencer, Dallas Burtraw, and Karen Palmer, 2002. "Efficient Emission Fees in the U.S. Electricity Sector." Discussion Paper 02-45, Resources for the Future, Washington, DC, October.

Bovenberg, A. Lans, and Ruud A. de Mooij, 1994. "Environmental Levies and Distortionary Taxation." American Economic Review 84(4), 1085-9.

Bovenberg, A. Lans, and Lawrence H. Goulder, 2001. "Neutralizing the Adverse Industry Impacts of $\mathrm{CO}_{2}$ Abatement Policies: What Does It Cost?" In C. Carraro and G. Metcalf, eds., Behavioral and Distributional Effects of Environmental Policy, University of Chicago Press.

Bovenberg, A. Lans, and Lawrence H. Goulder, 2002. "Environmental Taxation and Regulation in a Second-Best Setting," In A. Auerbach and M. Feldstein, eds., Handbook of Public Economics, second edition, Amsterdam: North-Holland.

Burtraw, Dallas, Karen Palmer, Ranjit Bharvirkar, and Anthony Paul, 2002. "The Effect on Asset Values of the Allocation of Carbon Dioxide Emission Allowances." Discussion Paper 02-15, Resources for the Future, Washington, D.C., March.

Chirinko, Robert S., Steven M. Fazzari, and Andrew P. Meyer, 2002. "That Elusive Elasticity: A Long-Panel Approach to Estimating the Price Sensitivity of Business Capital." Working paper, Emory University, January.

Dinan, Terry M., 2003. "Shifting the Cost Burden of a Carbon Cap-and-Trade Program.” U.S. Congressional Budget Office, Washington, D.C., July.

Farrow, Scott, 1999. "The Duality of Taxes and Tradeable Permits: A Survey with Applications in Central and Eastern Europe." Environmental and Development Economics 4:519-535.

Freeman, A. Myrick, 1993. The Measurement of Environmental and Resource Values: Theory and Methods. Resources for the Future, Washington, D.C.

Fullerton, Don, and Gilbert E. Metcalf, 2001. "Environmental Controls, Scarcity Rents, and Pre-Existing Distortions." Journal of Public Economics 80(2):249-67. 
Goulder, Lawrence H., 1995. "Environmental Taxation and the 'Double Dividend:' A Reader's Guide," International Tax and Public Finance, 2(2), 157-183.

Goulder, Lawrence H., Ian W. H. Parry, and Dallas Burtraw, 1997. "RevenueRaising vs. Other Approaches to Environmental Protection: The Critical Significance of Pre-Existing Tax Distortions." RAND Journal of Economics 28(4):708_731.

Goulder, Lawrence H., Ian W. H. Parry, Roberton C. Williams III, and Dallas Burtraw, 1999. "The Cost-Effectiveness of Alternative Instruments for Environmental Protection in a Second-Best Setting," Journal of Public Economics 72(3):329-60.

Olson, Mancur, 1965. The Logic of Collective Action. Cambridge, Mass.: Harvard University Press.

Parry, Ian W. H., 1995. "Pollution Taxes and Revenue Recycling," Journal of Environmental Economics and Management 29, S64-S77.

Parry, Ian, and Wallace E. Oates, 2000. "Policy Analysis in the Presence of Distorting Taxes." Journal of Policy Analysis and Management 19(4):603-13.

Russek, Frank S., 1996. " "Labor Supply and Taxes." Working paper, Macroeconomic Analysis Division, Congressional Budget Office, Washington, D.C.

Smith, Anne E., Martin E. Ross, and W. David Montgomery, 2002. "Implications of Trading Implementation Design for Equity-Efficiency Trade-offs in Carbon Permit Allocations," Working paper, Charles River Associates, Washington, D.C., December.

Williams, Roberton C. III, 2002. "Prices vs. Quantities vs. Tradable Quantities," working paper, Department of Economics, University of Texas at Austin. 


\section{A Appendix}

\section{A.1 The market for the final good}

\section{A.1.1 Supply}

Competitive profit-maximizing behavior by the downstream industry yields

$$
\begin{aligned}
& P_{y} \frac{\delta h(. ; .)}{\delta V} \frac{\delta v(. ; .)}{\delta X}=P_{x}+T_{e} \frac{\delta e}{\delta X}, \\
& P_{y} \frac{\delta h(. ; .)}{\delta L_{y}}=W \\
& -T_{e} \frac{\delta e}{\delta w} \frac{\delta g}{\delta C_{a}}=P_{c} ;-T_{e} \frac{\delta e}{\delta w} \frac{\delta g}{\delta Y_{a}}=P_{y}, \\
& P_{y} \frac{\delta h(. ; .)}{\delta V} \frac{\delta v(. ; .)}{\delta K_{y}}=R_{y} .
\end{aligned}
$$

The right-hand side of (A.1) indicates that the cost of the intermediate input consists of two parts: the production costs of this input, $P_{x}$, and the emission tax levied on the additional emissions generated by the intermediate input.

Loglinearizing the production function of the downstream industry (4) and employing the first-order conditions (A.1), (A.2), (A.3), and (A.4) (and using the fact that the emission function (5) exhibits constant returns to scale), we find

$$
y=k_{y}+\left(1-\alpha_{k}^{y}\right)\left(l_{y}-k_{y}\right)+\left(1-\alpha_{v}^{y}\right)(x-v),
$$

where $\alpha_{k}^{y} \equiv R_{y} K_{y} /\left(R_{y} K_{y}+P_{x} X+T_{e} E+P_{c} C_{a}+P_{y} Y_{a}\right)$ and $\alpha_{v}^{y} \equiv\left(R_{y} K_{y}+P_{x} X+T_{e} E+P_{c} C_{a}+\right.$ $\left.P_{y} Y_{a}\right) / P_{y} Y=1-\left(W L_{y} / P_{y} Y\right)$.

With constant-returns-to-scale production and emission functions, the relative change in the output price is a weighted average of the relative changes in the input prices ${ }^{32}$

$$
p_{y}=\alpha_{v}^{y} \alpha_{k}^{y} r_{y}+\alpha_{x}^{y} p_{x}+\alpha_{e}^{y} t_{e}
$$

where $\alpha_{x}^{y} \equiv P_{x} X / P_{y} Y$ and $\alpha_{e}^{y} \equiv T_{e} E / P_{y} Y$ stand for the cost shares of, respectively, the direct production costs of the intermediate good and the emission tax.

Capital supply is given by ${ }^{33}$

$$
k_{y}=\sigma_{k}^{y} r_{y}
$$

${ }^{32}$ Note that wages and $P_{c}$ do not change. This implies that the costs of abatement do not change because we assume, in line with our assumption that the upstream and downstream industries are small compared to the rest of the economy, that the share of abatement produced by the downstream industry (i.e. $\left.Y_{a}\right)$ in aggregate abatement $g\left(C_{a} ; Y_{a}\right)$ is only infinitely small.

33 This assumes that all households are well diversified so that income effects can be ignored. Alternatively, one can assume that a share $\gamma_{y}$ of capital owners in the downtream industry is 
where $\sigma_{K}^{y}$ stands for the substitution elasticity between the industry-specific capital services in the final goods sector and the capital services in the rest of the economy. Using (A.4), (A.2), and (A.1) to eliminate $P_{y}$ and log-linearizing the results, we arrive at the following two equations

$$
\begin{aligned}
& x-k_{y}=\sigma_{v}\left[r_{y}-\left(\alpha_{x}^{y} /\left(\alpha_{v}^{y}\left(1-\alpha_{k}^{y}\right)\right)\right) p_{x}-\left(\alpha_{e}^{y} /\left(\alpha_{v}^{y}\left(1-\alpha_{k}^{y}\right)\right)\right) t_{e}\right], \\
& l_{y}-v=\sigma_{y}\left[\alpha_{k}^{y} r_{y}+\left(\alpha_{x}^{y} / \alpha_{v}^{y}\right) p_{x}+\left(\alpha_{e}^{y} / \alpha_{v}^{y}\right) t_{e}\right],
\end{aligned}
$$

where $\sigma_{V}$ stands for the substitution elasticity between the intermediate input and capital in the composite $v(. ;$.$) while \sigma_{Y}$ represents the substitution elasticity between labor and the nest $v(. ;$.$) in the production function h(. ;$.$) (see (4)). Substituting (A.7), (A.6), (A.8), and (A.9) into$ (A.5), we write the supply of the final good in terms of its price, the price of the intermediate good, and the emission tax

$$
y=\varepsilon_{s}^{y}\left(p_{y}-\alpha_{x}^{y} p_{x}-\alpha_{e}^{y} t_{e}\right)-\left\{\left[\left(1-\alpha_{v}^{y}\right) \sigma_{y}-\sigma_{v}\right] / \alpha_{v}^{y}\right\} p_{y},
$$

where $\varepsilon_{s}^{y} \equiv\left[\sigma_{k}^{y}+\sigma_{v}\right] /\left[\alpha_{v}^{y} \alpha_{k}^{y}\right]$ is the supply elasticity. This supply elasticity becomes infinite if capital (i.e. the 'fixed' factor) does not play a role in production (i.e. $\alpha_{k}^{y}=0$ or $\alpha_{v}^{y}=0$ ), if industry-specific capital is a perfect substitute for capital in the rest of the economy (i.e. $\sigma_{K}^{y} \Rightarrow \infty$ so that adjustment costs are absent), or if intermediate inputs are a perfect substitute for the imperfectly mobile factor (i.e. capital) (i.e. $\sigma_{v} \Rightarrow \infty$ ). In all these cases, the immobile factor does not constrain production of the final good.

In a similar way, we can derive the impact on the demand for the intermediate good (using (A.7), (A.6), and (A.8)) as

$$
x=\varepsilon_{s}^{y}\left(p_{y}-\alpha_{x}^{y} p_{x}-\alpha_{e}^{y} t_{e}\right)-\sigma_{v}\left(\frac{\alpha_{x}^{y}}{\alpha_{v}^{y}\left(1-\alpha_{k}^{y}\right)} p_{x}+\frac{\alpha_{e}^{y}}{\alpha_{v}^{y}\left(1-\alpha_{k}^{y}\right)} t_{e}\right)
$$

Linearizing the emission function (5) and the first-order condition for abatement (A.3), we find emissions in terms of the emission tax and the prices of the final and intermediate goods ${ }^{34}$

$$
\begin{aligned}
e= & x-\frac{\alpha_{v}^{y}\left(1-\alpha_{k}^{y}\right)-\alpha_{x}^{y}-\alpha_{e}^{y}}{\alpha_{v}^{y}\left(1-\alpha_{k}^{y}\right)-\alpha_{x}^{y}} \sigma_{e} t_{e}= \\
& \varepsilon_{s}^{y}\left(p_{y}-\alpha_{x}^{y} p_{x}-\alpha_{e}^{y} t_{e}\right)-\sigma_{v}\left(\frac{\alpha_{x}^{y}}{\alpha_{v}^{y}\left(1-\alpha_{k}^{y}\right)} p_{x}+\frac{\alpha_{e}^{y}}{\alpha_{v}^{y}\left(1-\alpha_{k}^{y}\right)} t_{e}\right)-\frac{\alpha_{v}^{y}\left(1-\alpha_{k}^{y}\right)-\alpha_{x}^{y}-\alpha_{e}^{y}}{\alpha_{v}^{y}\left(1-\alpha_{k}^{y}\right)-\alpha_{x}^{y}} \sigma_{e} t_{e}
\end{aligned}
$$

completely specialized in this sector (i.e. only derives income from capital in this sector). In that case the elasticity $\sigma_{k}^{y}$ in the following equation is replaced by $\left(1-\gamma_{y}\right) \sigma_{k}^{y}+\gamma_{y} \varepsilon_{u}$, where $\varepsilon_{u}$ stands for the uncompensated elasticity of aggregate capital supply with respect to the rate of return.

${ }^{34}$ Without an initial emission tax, the firm does not abate in the initial equilibrium (i.e. $\left.C_{a}=Y_{a}=0\right)$ so that $\alpha_{v}^{y}\left(1-\alpha_{k}^{y}\right)-\alpha_{x}^{y}-\alpha_{e}^{y}=0$. Hence, the relative change in emissions remains finite even though $t_{e}$ goes to infinity if the initial emission tax is zero. 
where $\sigma_{e}$ represents the substitution elasticity between the intermediate input $X$ and abatement $g\left(C_{a} ; Y_{a}\right)$ in the emission function $e($,$) (see (5)). The second term at the first right-hand$ side of (A.12) shows that the pollution tax reduces emissions per unit of intermediate input. This reduction is especially large if abatement is important (i.e. the cost share of abatement, $\frac{\alpha_{v}^{y}\left(1-\alpha_{k}^{y}\right)-\alpha_{x}^{y}-\alpha_{e}^{y}}{\alpha_{v}^{y}\left(1-\alpha_{k}^{y}\right)-\alpha_{x}^{y}}=\frac{P_{c} C_{a}+P_{y} Y_{a}}{P_{c} C_{a}+P_{y} Y_{a}+T_{e} E}$, is large) and if substitution between abatement and intermediate input is easy (i.e. $\sigma_{e}$ is large).

\section{A.1.2 Demand}

Maximization of the utility function yields

$$
\frac{\delta g}{\delta Y} / \frac{\delta g}{\delta C}=\frac{P_{y}}{P_{c}} .
$$

Log-linearization of this equation yields the demand function

$$
y=-\sigma_{g} p_{y}
$$

where $\sigma_{g}$ represents the substitution elasticity between the final good $Y$ and other consumption goods $C$ in the household sub-utility function $g(.,$.$) (see (8)).$

\section{A.1.3 Equilibrium}

Equilibrium on the market for the final good implies that demand (i.e. the right-hand side of (A.14) equals the right-hand side of (A.10)). This yields the price of the final good in terms of the demand price of the intermediate good

$$
p_{y}=\frac{\varepsilon_{s}^{y}}{\varepsilon_{s}^{y}+\varepsilon_{d}^{y}}\left[\alpha_{x}^{y} p_{x}+\alpha_{e}^{y} t_{e}\right]
$$

where $\varepsilon_{d}^{y} \equiv \sigma_{g}+\left[\left(1-\alpha_{v}^{y}\right) \sigma_{y}-\sigma_{v}\right] / \alpha_{v}^{y}$. The final goods sector can shift the entire burden of higher costs (due to either a higher emission tax or a higher price of the intermediate input) forward to consumers if it can as easily substitute away from the intermediate good as the consumers can substitute away from the dirty final good (i.e. $\sigma_{y}=\sigma_{v}=\sigma_{g}$ ). However, if consumers have more opportunities to substitute away from the final good than final good producers have to substitute away from the intermediate input (i.e. $\sigma_{g}>\sigma_{y}=\sigma_{v}$ so that $\varepsilon_{d}^{y}>0$ ), the final good industry has to absorb some of the burden of the higher costs of intermediate inputs and emissions. This share becomes larger if a smaller elasticity $\sigma_{k}^{y}$ depresses the supply elasticity $\varepsilon_{s}^{y} \equiv\left[\sigma_{k}^{y}+\sigma_{v}\right] /\left[\alpha_{v}^{y} \alpha_{k}^{y}\right]$.

The impact on the output of the final goods industry is found by substituting (A.15) into (A.14) to eliminate the price of the final good $p_{y}$ :

$$
y=\frac{-\sigma_{G} \varepsilon_{s}^{y}}{\varepsilon_{s}^{y}+\varepsilon_{d}^{y}}\left[\alpha_{x}^{y} p_{x}+\alpha_{e}^{y} t_{e}\right] .
$$


Higher costs of the intermediate input substantially depress the output of the final good if both the demand elasticity $\sigma_{G}$ and the supply elasticity $\varepsilon_{s}^{y}$ are large.

\section{A.1.4 Distribution}

The impact on the producer surplus of the final goods sector is given by ${ }^{35}$

$$
\alpha_{v}^{y} \alpha_{k}^{y} r_{y}=p_{y}-\alpha_{x}^{y} p_{x}-\alpha_{e}^{y} t_{e}=-\frac{\varepsilon_{d}^{y}}{\varepsilon_{s}^{y}+\varepsilon_{d}^{y}}\left[\alpha_{x}^{y} p_{x}+\alpha_{e}^{y} t_{e}\right]
$$

where the first equality follows from (A.6) and the second equality by substitution of (A.15) to eliminate $p_{y}$. Rentals in the final goods sector thus decline with higher costs of the intermediate input and emissions if the substitution possibilities of consumers exceed those of producers (i.e., $\sigma_{g}>\sigma_{y}=\sigma_{v}$ so that $\left.\varepsilon_{d}^{x}>0\right)$. Rentals increase, however, if capital is a good substitute for the polluting intermediate good (i.e. $\sigma_{v}$ is large) while consumers can not easily substitute away from the final good (i.e. $\sigma_{g}$ is small) and producers cannot easily substitute labor for the composite $v\left(K_{y} ; X\right)$ (i.e. $\sigma_{y}$ is small) so that $\varepsilon_{d}^{y} \equiv \sigma_{g}+\left[\left(1-\alpha_{v}^{y}\right) \sigma_{y}-\sigma_{v}\right] / \alpha_{v}^{y}<0$. In this case, the demand for capital rises on account of a positive substitution effect as producers substitute capital (rather than labor) for the polluting input. At the same time, production of the final good does not decline much as households do not respond much to the higher price of the final good. With a substantial positive substitution effect on capital demand thus dominating a small (in absolute value) scale effect on capital demand, the demand for capital rises thereby boosting the rental rate.

\section{A.2 The market for the intermediate good}

\section{A.2.1 Demand}

Demand for the intermediate good can be written in terms of the price of intermediate goods by substituting (A.15) into (A.11) to eliminate $p_{y}$ :

$$
x^{d}=-\varepsilon_{d}^{x}\left[p_{x}+\frac{\alpha_{e}^{y}}{\alpha_{x}^{y}} t_{e}\right],
$$

where $\varepsilon_{d}^{x} \equiv\left[\alpha_{x}^{y}\left(\frac{\varepsilon_{s}^{y} \varepsilon_{d}^{y}}{\varepsilon_{s}^{y}+\varepsilon_{d}^{y}}\right)+\left(\frac{\alpha_{x}^{y}}{\alpha_{v}^{y}\left(1-\alpha_{k}^{y}\right)}\right) \sigma_{v}\right]$ is the price elasticity of the demand for the intermediate good. A higher price of the intermediate good depresses the demand for the intermediate good through two channels: a negative 'scale' effect on the output of the final goods sector (i.e. the first term in the square brackets at the right-hand side of the definition of the demand elasticity)) and a negative substitution effect (i.e. the second term in the square brackets at the right-hand side of the definition of the demand elasticity)).

\footnotetext{
${ }^{35}$ Producers optimally set the capital stock according to (A.4). Accordingly, the envelope theorem implies that a change in the capital stock does not directly affect the producer surplus.
} 


\section{A.2.2 Supply}

Loglinearizing the production function of the upstream industry (1), we find

$$
x^{s}=k_{x}+\left(1-\alpha_{k}^{x}\right)\left(l_{x}-k_{x}\right),
$$

where $\alpha_{k}^{x} \equiv R_{x} K_{x} / P_{x} X$ stands for the share of capital in output of the upstream sector. With a constant-returns-to-scale production function, the relative change in the output price is a weighted average of the relative changes in the input prices (note that wages do not change)

$$
p_{x}=\alpha_{k}^{x} r_{x}
$$

Capital supply is given by ${ }^{36}$

$$
k_{x}=\sigma_{k}^{x} r_{x}
$$

where $\sigma_{k}^{x}$ stands for the substitution elasticity between the industry-specific capital services in the intermediate goods industry and the capital services in the rest of the economy.

Using (2) and (3) to eliminate $P_{x}$ and log-linearizing the results, we arrive at

$$
l_{x}-k_{x}=\sigma_{x} r_{x}
$$

where $\sigma_{x}$ stands for the substitution elasticity between the two inputs in the production of the intermediate good.

Substituting (A.21), (A.22), and (A.20) into (A.19) to eliminate $k_{x},\left(l_{x}-k_{x}\right)$, and $r_{x}$, we write the supply of the final good in terms of its price and the demand price of the intermediate good

$$
x^{s}=\varepsilon_{s}^{x} p_{x},
$$

where $\varepsilon_{s}^{x} \equiv\left[\sigma_{k}^{x}+\left(1-\alpha_{k}^{x}\right) \sigma_{x}\right] / \alpha_{k}^{x}$ denotes the supply elasticity. This elasticity becomes infinite if capital (i.e. the 'fixed' factor) does not play a role in production (i.e. $\alpha_{k}^{x}=0$ ), if capital is a perfect substitute for capital in the rest of the economy (i.e. $\sigma_{k}^{x} \Rightarrow \infty$ so that adjustment costs are absent), or if mobile labor is a perfect substitute for the imperfectly mobile factor (i.e. capital) (i.e. $\sigma_{x} \Rightarrow \infty$ ). In all these cases, the immobile factor does not constrain production of the final good.

\footnotetext{
${ }^{36}$ This assumes that all households are well diversified so that income effects can be ignored. Alternatively, one can assume that a share $\gamma_{x}$ of capital owners in the upstream industry is completely specialized in this sector (i.e. only derives income from capital in this sector). In that case the elasticity $\sigma_{k}^{x}$ in the following equation is replaced by $\left(1-\gamma_{x}\right) \sigma_{k}^{x}+\gamma_{x} \varepsilon_{u}$, where $\varepsilon_{u}$ stands for the elasticity of aggregate capital supply with respect to the rate of return.
} 


\section{A.2.3 Equilibrium}

The demand for the intermediate good is given by (A.18). The supply is given by (A.23). Setting demand equal to supply, we arrive at

$$
p_{x}=-\left(\frac{\varepsilon_{d}^{x}}{\varepsilon_{d}^{x}+\varepsilon_{s}^{x}}\right) \frac{\alpha_{e}^{y}}{\alpha_{x}^{y}} t_{e},
$$

and

$$
\alpha_{x}^{y} p_{x}+\alpha_{e}^{y} t_{e}=\left(\frac{\varepsilon_{s}^{x}}{\varepsilon_{d}^{x}+\varepsilon_{s}^{x}}\right) \alpha_{e}^{y} t_{e} .
$$

Demand bears most of the emission tax burden (i.e. the demand price rises substantially (as indicated by the sign of $\left.\alpha_{x}^{y} p_{x}+\alpha_{e}^{y} t_{e}\right)$ while the supply price $P_{x}$ does not decline much) if demand is inelastic compared to supply (i.e. if $\varepsilon_{d}^{x}$ is small compared to $\varepsilon_{s}^{x}$ ).

We can now write the reduced form for the price of the final good $p_{y}$. Substitution of (A.25) into (A.15) yields

$$
p_{y}=\left(\frac{\varepsilon_{s}^{x}}{\varepsilon_{d}^{x}+\varepsilon_{s}^{x}}\right)\left(\frac{\varepsilon_{s}^{y}}{\varepsilon_{s}^{y}+\varepsilon_{d}^{y}}\right) \alpha_{e} t_{e} .
$$

The effects on the output of the upstream sector are given by (substitute (A.25) into (A.18) to eliminate $p_{x}$ )

$$
x=-\left(\frac{\varepsilon_{s}^{x} \varepsilon_{d}^{x}}{\varepsilon_{d}^{x}+\varepsilon_{s}^{x}}\right) \frac{\alpha_{e}^{y}}{\alpha_{x}^{y}} t_{e} .
$$

Output of the intermediate good falls substantially on account of the emission tax if both the demand and supply elasticities are large. This is the case if capital is mobile and demand for the

final good is elastic. Moreover, input substitution between capital and the dirty intermediate input in the downstream industry increases the decline in output of the intermediate goods industry.

\section{A.2.4 Emission reductions}

The impact on pollution is found by substituting (A.27) into the first equality in (A.12) to eliminate $x$

$$
e=-\left[\left(\frac{\varepsilon_{s}^{x} \varepsilon_{d}^{x}}{\varepsilon_{d}^{x}+\varepsilon_{s}^{x}}\right) \frac{\alpha_{e}^{y}}{\alpha_{x}^{y}}+\sigma_{e} \frac{\alpha_{v}^{y}\left(1-\alpha_{k}^{y}\right)-\alpha_{x}^{y}-\alpha_{e}^{y}}{\alpha_{v}^{y}\left(1-\alpha_{k}^{y}\right)-\alpha_{x}^{y}}\right] t_{e} .
$$

Inverting this equation, we can write the tax rate in terms of the pollution reduction. In this way, we can write the results in terms of the required reduction in pollution rather than 
the tax rate. Hence, we can alternatively parameterize environmental policy by changes in the pollution tax $t_{e}$ or by changes in emission permits $e$. In particular, we can relate the required cost increase (as a ratio of the initial price of the output of the downstream industry) $\alpha_{e}^{y} t_{e}$ to the required emission cut $a=-e$ :

$$
\alpha_{e}^{y} t_{e}=\kappa a,
$$

where $\kappa \equiv 1 /\left[\left(\frac{\varepsilon_{s}^{x} \varepsilon_{d}^{x}}{\varepsilon_{d}^{x}+\varepsilon_{s}^{x}}\right) \frac{1}{\alpha_{x}^{y}}+\sigma_{e} \frac{\alpha_{v}^{y}\left(1-\alpha_{k}^{y}\right)-\alpha_{x}^{y}-\alpha_{e}^{y}}{\alpha_{e}^{y}\left[\alpha_{v}^{y}\left(1-\alpha_{k}^{y}\right)-\alpha_{x}^{y}\right]}\right]$. The denominator in this definition of $\kappa$ includes the various channels through which emission can be cut, namely (i) abatement (which is the second term in the denominator), (ii) output of the final good (which is implicit in the first term between square brackets in the definition of $\varepsilon_{d}^{x}$ (i.e $\left.\varepsilon_{d}^{x} \equiv\left[\alpha_{x}^{y}\left(\frac{\varepsilon_{s}^{y} \varepsilon_{d}^{y}}{\varepsilon_{s}^{y}+\varepsilon_{d}^{y}}\right)+\left(\frac{\alpha_{x}^{y}}{\alpha_{v}^{y}\left(1-\alpha_{k}^{y}\right)}\right) \sigma_{v}\right]\right)$ and thus affects the first term in the denominator of (A.29)), and (iii) input substitution between capital and the intermediate input in the downstream industry (this is implicit in the second term between square brackets in the definition of $\left.\varepsilon_{d}^{x}\right)$. The emission cost increase $\alpha_{e}^{y} t_{e}$ required to attain a certain emission cut $(-e)$ falls as these three channels become more effective.

\section{A.3 Distributional impacts}

We now analyze the distributional impacts of the environmental policy. The non-environmental welfare impacts consist of the change in the after-tax producer surplus in the upstream industry $(P S X)$, the change in the after-tax producer surplus in the downstream industry $(P S Y)$, and the change in non-environmental (after-tax) consumer surplus $(N C S)$. It will be convenient to express these three components of non-environmental welfare relative to $P_{y} Y$, the initial before-tax value of the output of the downstream industry $Y$. We can express these changes as

$$
\begin{aligned}
& p s x \equiv \frac{d P S X}{P_{y} Y}=(1-T)\left[\alpha_{x}^{y} p_{x}+\pi_{x}\right]=(1-T)\left[\alpha_{x}^{y} \alpha_{k}^{y} r_{x}+\pi_{x}\right], \\
& p s y \equiv \frac{d P S Y}{P_{y} Y}=(1-T)\left[p_{y}-\alpha_{x}^{y} p_{x}-\alpha_{e}^{y} t_{e}+\pi_{y}\right]=(1-T)\left[\alpha_{v}^{y} \alpha_{k}^{y} r_{y}+\pi_{y}\right], \\
& n c s \equiv \frac{d N C S}{P_{y} Y}=-(1-T)\left[p_{y}+(t / \beta)\right],
\end{aligned}
$$

where $\pi_{i}$ denotes lump-sum compensation (which is assumed to be taxed at the factor tax $T$ ) to sector $i ; i=x, y$ (expressed relative to $P_{y} Y$ ) and $t \equiv d T /(1-T)$. $\beta \equiv P_{y} Y / Q$, where $Q$ is aggregate factor income (before tax). This share goes to zero in our model in which the downstream and upstream sectors are very small compared to the rest of the economy. ${ }^{37}$

To arrive at the reduced-form equations, we substitute (A.24), (A.25), and (A.26) (and using (A.29) to eliminate $\left.\alpha_{e}^{y} t_{e}\right)$ into the second right-hand sides of (A.30) and (A.31):

$$
p s x /(1-T) \equiv-\left(\frac{\varepsilon_{d}^{x}}{\varepsilon_{d}^{x}+\varepsilon_{s}^{x}}\right) \kappa a+\pi_{x},
$$

${ }^{37}$ Also the relative change in the factor tax, $t$, goes to zero. However, the ratio $t / \beta$ in (A.32) is well defined. 


$$
p s y /(1-T)=-\left(\frac{\varepsilon_{s}^{x}}{\varepsilon_{d}^{x}+\varepsilon_{s}^{x}}\right)\left(\frac{\varepsilon_{d}^{y}}{\varepsilon_{s}^{y}+\varepsilon_{d}^{y}}\right) \kappa a+\pi_{y} .
$$

Setting these equations equal to zero, we find $\pi_{x}$ and $\pi_{y}$ required to ensure equity value neutrality in both sectors. The first terms at the right-hand sides of these expressions show which shares of the emission cost increase is born by the upstream and downstream industries, respectively.

\section{A.4 Efficiency costs}

To find $n c s$, we derive $t / \beta$ from the government budget constraint. This latter constraint is given by

$$
g+(1-T) \pi=\alpha_{e}^{y}\left(t_{e}(1-T)+e\right)+T q+(1-T)(t / \beta)
$$

where $q \equiv[\alpha k+(1-\alpha) l] / \beta$ is the change in aggregate factor supply measured relative to the initial output of the downstream industry ( $\alpha$ is the share of capital income in aggregate value added and $k$ and $l$ represent aggregrate capital and labor supply, respectively), $g$ stands for the change in government spending (expressed relative to the initial output of the downstream industry $Y)$ and $\pi \equiv \pi_{x}+\pi_{y}$. The first term $(1-T)$ at the right-hand side of this equation follows from the no-profit constraint, which implies that a higher pollution tax implies lower factor income (and thus lower factor tax revenue since factor income is taxed at rate $T$ ).

Substituting (A.35) into (A.32) to eliminate $t$, we find for the overall non-environmental welfare effect $\psi \equiv p s x+p s y+n c s$ (using the first equalities after the definitions in (A.30), (A.31), and (A.32):

$$
\psi=\alpha_{e}^{y} e+T q-g
$$

where we also ignore the welfare effects of higher government spending (just as we ignore the welfare effects of better environmental quality as a result of less pollution).

Aggregate factor supply is

$$
q \beta=-\varepsilon_{u}\left[t+\beta \alpha_{e}^{y} t_{e}\right]+\varepsilon_{I}[\pi \beta],
$$

where $\varepsilon_{I}$ is the income elasticity of aggregate factor supply. Using (A.35) to eliminate $t$ from this equation, we establish

$$
q(1-T)=\left(\frac{1}{1-\varepsilon_{u}[T /(1-T)]}\right)\left[\varepsilon_{u}\left(\alpha_{e}^{y} e-g\right)-\varepsilon_{c} \pi(1-T)\right] .
$$

Substitution of (A.38) into (A.36) yields

$$
\psi=\lambda\left(\alpha_{e}^{y} e-g\right)-\mu \pi(1-T)
$$

where we have used the definitions of $\lambda$ and $\mu$ (see (9) and (10)). 
We find the effect on the consumer surplus by using $n c s=\psi-p s x-p s y$ and substituting (A.39), (A.33), and (A.34) to arrive at

$$
n c s=-\lambda\left(\alpha_{e}^{y} a+g\right)-\left(\frac{1+\varepsilon_{I}[T /(1-T)]}{1-\varepsilon_{u}[T /(1-T)]}\right) \pi(1-T)+\left[1-\left(\frac{\varepsilon_{s}^{x}}{\varepsilon_{d}^{x}+\varepsilon_{s}^{x}}\right)\left(\frac{\varepsilon_{s}^{y}}{\varepsilon_{s}^{y}+\varepsilon_{d}^{y}}\right)\right] \kappa a(1-T) .
$$

The last term represents the redistributional effects of an environmental tax recycled as lower factor taxes. If the supply elasticities $\varepsilon_{s}^{x}$ and $\varepsilon_{s}^{y}$ are less than infinite, the sector-specific factors pay part of the tax while factors outside the sectors benefit from the recycling of this tax burden.

\section{A.5 Efficiency and equity value neutrality}

We are now ready to combine the efficiency results with those for equity by exploring the efficiency costs of equity value neutrality (EVN). If for both sectors EVN is imposed, we derive from (A.33) and (A.34) that $\pi=\pi_{x}+\pi_{y}=\left[1-\left(\frac{\varepsilon_{s}^{x}}{\varepsilon_{d}^{x}+\varepsilon_{s}^{x}}\right)\left(\frac{\varepsilon_{s}^{y}}{\varepsilon_{s}^{y}+\varepsilon_{d}^{y}}\right)\right] \kappa a$. Substituting this, $g=0$ and $-e=a$ into (A.39), we arrive at

$$
\psi / a=-\lambda \alpha_{e}^{y}-\mu(1-T)\left[1-\left(\frac{\varepsilon_{s}^{x}}{\varepsilon_{d}^{x}+\varepsilon_{s}^{x}}\right)\left(\frac{\varepsilon_{s}^{y}}{\varepsilon_{s}^{y}+\varepsilon_{d}^{y}}\right)\right] \kappa .
$$

With sector-specific production factors shielded from any losses, the efficiency effect corresponds to the loss of consumer surplus (i.e. ncs $=\psi$ ).

Expression (A.41) shows the efficiency loss as a result of the environmental improvement consists of two terms, namely, first, a loss as a result of the erosion of the environmental tax base and, second, an efficiency loss as a result of paying lump-sum compensation to the sectorspecific factors in the polluting industries. The ratio of the two terms, $\chi$, can be interpreted as the additional efficiency cost of achieving equity value neutrality in terms of the marginal efficiency costs of achieving environmental improvement

$$
\chi \equiv \frac{\mu \pi(1-T)}{\lambda \alpha_{e}^{y} a}=\varepsilon_{c} T \frac{\left[1-\left(\frac{\varepsilon_{s}^{x}}{\varepsilon_{d}^{x}+\varepsilon_{s}^{x}}\right)\left(\frac{\varepsilon_{s}^{y}}{\varepsilon_{s}^{y}+\varepsilon_{d}^{y}}\right)\right] \kappa}{\alpha_{e}^{y}},
$$

where we have used (9), (10), and $\pi=\pi_{x}+\pi_{y}=\left[1-\left(\frac{\varepsilon_{s}^{x}}{\varepsilon_{d}^{x}+\varepsilon_{s}^{x}}\right)\left(\frac{\varepsilon_{s}^{y}}{\varepsilon_{s}^{y}+\varepsilon_{d}^{y}}\right)\right] \kappa a$.

\section{A.6 Compensation ratios}

The government collects tax revenues. The change in potential tax revenues (again expressed relative to the initial output of the downstream industry $Y$ ) is

$$
t r^{n} \equiv \frac{d\left(T_{e} E\right)}{P_{y} Y}=\alpha_{e}^{y}\left((1-T) t_{e}+e\right)+T q,
$$


where $q \equiv[\alpha k+(1-\alpha) l] / \beta$ is the change in aggregate factor supply expressed relative to the initial output of the downstream industry ( $\alpha$ is the share of capital income in aggregate value added).

Setting $g=0$ and substituting (A.38) into (A.43), we arrive at

$$
\operatorname{tr}^{n}=\alpha_{e}^{y}\left[t_{e}(1-T)+\lambda e\right]-\mu \pi(1-T)
$$

The net compensation ratios are defined as the share of net revenue that needs to be paid in net compensation $(1-T) \pi_{i}$, i.e. $s_{i}^{n} \equiv(1-T) \pi_{i} / \operatorname{tr}^{n}(\mathrm{i}=\mathrm{x}, \mathrm{y})$. By substituting $a=-e$, (A.33) to find $\pi_{x}$ and $\pi_{y}$ required to achieve equity value neutrality in the upstream and downstream industries respectively, and (A.29) to eliminate $\alpha_{e}^{y} t_{e}$, we arrive at the net compensation ratios for the two industries.

$$
\begin{aligned}
\theta_{x}^{n}=\left(\frac{\varepsilon_{d}^{x}}{\varepsilon_{d}^{x}+\varepsilon_{s}^{x}}\right) / & {\left.\left[1-\lambda \alpha_{e}^{y} /[\kappa(1-T)]-\mu\left(\frac{\varepsilon_{d}^{x}}{\varepsilon_{d}^{x}+\varepsilon_{s}^{x}}\right)\right)\right], } \\
\theta_{y}^{n}= & \left(\frac{\varepsilon_{s}^{x}}{\varepsilon_{d}^{x}+\varepsilon_{s}^{x}}\right)\left(\frac{\varepsilon_{d}^{y}}{\varepsilon_{s}^{y}+\varepsilon_{d}^{y}}\right) \\
& \left./\left[1-\lambda \alpha_{e}^{y} /[\kappa(1-T)]-\mu\left(\frac{\varepsilon_{s}^{x}}{\varepsilon_{d}^{x}+\varepsilon_{s}^{x}}\right)\left(\frac{\varepsilon_{d}^{y}}{\varepsilon_{s}^{y}+\varepsilon_{d}^{y}}\right)\right)\right] .
\end{aligned}
$$

We can also define gross tax revenues as follows $t^{g} \equiv \frac{d\left(T_{e} E\right)}{P_{y} Y}=\alpha_{e}^{y}\left(t_{e}+e\right)$. We thus do not take into account the impact on the base of the factor taxes. We can compute the gross compensation ratios as the share of gross revenue that needs to be paid in gross compensation $\pi_{i}$, i.e. $s_{i}^{g} \equiv \pi_{i} / t r^{g}(\mathrm{i}=\mathrm{x}, \mathrm{y})$. This yields

$$
\begin{aligned}
& \theta_{x}^{g}=\left(\frac{\varepsilon_{d}^{x}}{\varepsilon_{d}^{x}+\varepsilon_{s}^{x}}\right) /\left[1-\alpha_{e}^{y} / \kappa\right], \\
& \theta_{y}^{g}=\left(\frac{\varepsilon_{s}^{x}}{\varepsilon_{d}^{x}+\varepsilon_{s}^{x}}\right)\left(\frac{\varepsilon_{d}^{y}}{\varepsilon_{s}^{y}+\varepsilon_{d}^{y}}\right) /\left[1-\alpha_{e}^{y} / \kappa\right] .
\end{aligned}
$$

We observe that net compensation ratios exceed the gross compensation ratios if initial factor taxes are positive (i.e. $T, \mu>0$, see (10)) and the marginal cost of public funds exceeds unity (i.e. $\lambda>1$ because $\varepsilon_{u}>0$, see (9)). To illustrate, if we start from an initial equilibrium without any environmental policy (i.e. $\alpha_{e}^{y}=0$ ), the gross and net compensation ratios in the upstream sector are $\left(\frac{\varepsilon_{d}^{x}}{\varepsilon_{d}^{x}+\varepsilon_{s}^{x}}\right)$ and $\left.\left(\frac{\varepsilon_{d}^{x}}{\varepsilon_{d}^{x}+\varepsilon_{s}^{x}}\right) /\left[1-\mu\left(\frac{\varepsilon_{d}^{x}}{\varepsilon_{d}^{x}+\varepsilon_{s}^{x}}\right)\right)\right]$, respectively.

The (marginal) compensation ratios raise with the level of abatement as long as the policy yields net revenue (i.e. as long as we do not hit the top of the Laffer curve). ${ }^{38}$ The reason is that in this interval more abatement raises the share $\alpha_{e}^{y}$. Thus, whereas more initial

\footnotetext{
${ }^{38}$ If the policy yields less revenue, the compensation ratios are not well defined.
} 
abatement (by raising $\alpha_{e}^{y}$ ) tends to reduce the additional efficiency costs ratio $\chi$, it typically reduces the compensation ratio. Indeed, we can relate the compensation ratios to the additional efficiency cost as follows for the two sectors separately: $\chi_{i} \equiv \frac{\mu \pi_{x}(1-T)}{\lambda \alpha_{e}^{y} a}=\varepsilon_{c} T s_{i}^{g}\left[\kappa-\alpha_{e}^{y}\right] / \alpha_{e}^{y}=$ $\left.\varepsilon_{c} T s_{i}^{n}\left[\kappa-\lambda \alpha_{e}^{y} /[(1-T)]-\mu \kappa\left(\frac{\varepsilon_{d}^{x}}{\varepsilon_{d}^{x}+\varepsilon_{s}^{x}}\right)\right)\right] / \alpha_{e}^{y}$. The tax-base erosion effect $\alpha_{e}^{y}$ increases the denominator of the ratio $\chi$ but decreases tax revenues and therefore the denominator of the compensation ratios. Thus, the efficiency ratio is large compared to the gross compensation ratio if distortionary taxes and compensated wage elasticities of labor are large. At the same time, initial abatement should be small so that marginal economy-wide efficiency costs are small while the policy yields substantial additional revenues $\left(\kappa>\alpha_{e}^{y}\right.$ so that Laffer curve is upward sloping). 
Figure 1

Rents and the Gross Compensation Ratio

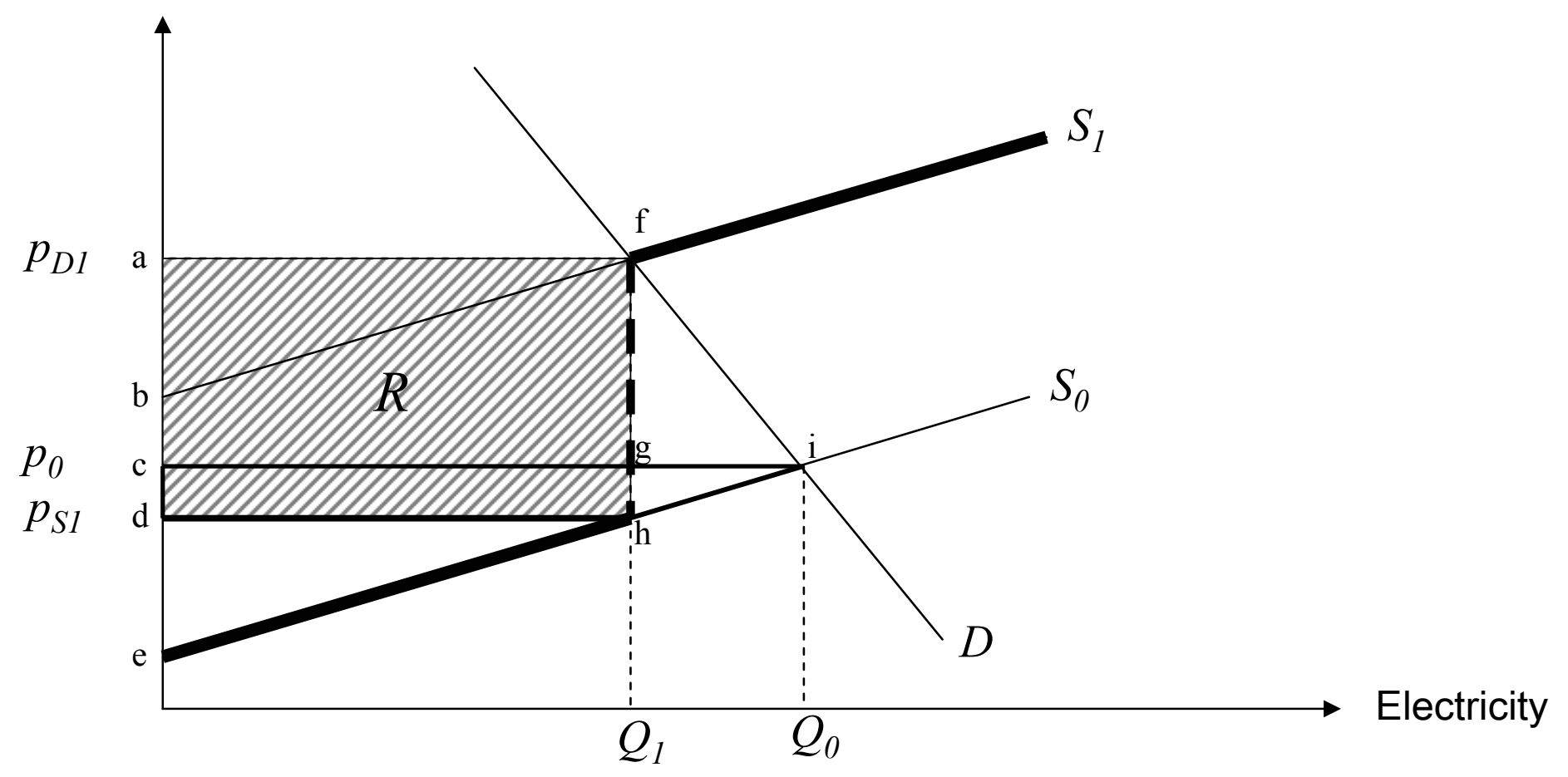


Table 1

Benchmark Input-Output Flows for the Numerical Model ${ }^{1}$

\begin{tabular}{|c|c|c|c|c|c|}
\hline & \multicolumn{3}{|c|}{ Use of Input by Industry ... } & \multirow[b]{2}{*}{$\begin{array}{l}\text { Total } \\
\text { Receipts to } \\
\text { Each Input }\end{array}$} & \multirow[b]{2}{*}{ Endowments $^{3}$} \\
\hline & $\mathrm{X}$ & Y & $\mathrm{C}$ & & \\
\hline \multicolumn{6}{|l|}{ Input $^{2}$ : } \\
\hline $\mathrm{X}$ & 0.0 & 27.1 & 0.0 & 27.1 & \\
\hline $\mathrm{L}$ & 2.6 & 11.8 & 1765.3 & 1779.7 & 5249.8 \\
\hline K & 13.7 & 44.0 & 712.4 & 770.1 & 2271.5 \\
\hline factor taxes & 10.8 & 48.0 & 1651.8 & 1710.6 & \\
\hline $\begin{array}{l}\text { Total Input } \\
\text { Payments by } \\
\text { Each Industry }\end{array}$ & 27.1 & 130.9 & 4129.5 & & \\
\hline $\mathrm{SO}_{2}$ Emissions $^{4}$ & & 15.2 & & & \\
\hline
\end{tabular}

${ }^{1}$ In billions of year-2000 dollars per year except where otherwise noted

${ }^{2}$ Inputs of labor and capital are net of factor taxes.

${ }^{3}$ Endowments correspond to $\bar{L}$ and $\bar{K}$ in equation (32) of text.

${ }^{4}$ Millions of tons per year

Sources: Except for the emissions data, these flows are based on the Department of Commerce Bureau of Economic Analysis's Benchmark Input \& Output Tables for 1992. The emissions data are from Table 12.6 of the Energy Information Agency’s Annual Energy Review 1999. 
Table 2

\title{
Central Case Parameter Values
}

\author{
parameters for Y industry \\ $\beta_{e} \quad$ ease of end-of pipe treatment -- scale parameter $\quad 2.0$ \\ $\rho_{e} \quad$ ease of end-of-pipe treatment -- curvature parameter $\quad 0.6$ \\ $\sigma_{y} \quad$ elasticity of substitution between \\ $v$ and $L$ in production of $Y \quad 0.75$ \\ $\sigma_{v} \quad$ elasticity of substitution between \\ $X$ and $K$ in production of $v$
}

parameters for $X$ and $C$ industries

$\sigma_{x} \quad$ elasticity of substitution between

$K$ and $L$ in production of $X \quad 1.0$

$\sigma_{c} \quad$ elasticity of substitution between

$v$ and $L$ in production of $C$

other production-related parameters

$\sigma_{k} \quad$ ease of capital movement $\quad-1.0$

$\gamma \quad$ ratio of potential to actual capital $\quad 1.77$

utility function parameters

$\sigma_{u} \quad$ elasticity of substitution between

$G(C-Y$ composite $)$ and $H(L-K)$ composite $\quad 0.66$

$\sigma_{g} \quad$ elasticity of substitution between

$C$ and $Y$

0.9

$\sigma_{h} \quad$ elasticity of substitution between

$L$ and $K$

0.9 
Table 3

\section{Policy Experiments}

\begin{tabular}{|l|l|l|l|}
\hline \multirow{2}{*}{ Experiment } & \multirow{2}{*}{$\begin{array}{l}\text { Instrument for } \\
\text { Government Budget } \\
\text { Balance }\end{array}$} & \multicolumn{2}{l|}{ Instrument for Equity Value Neutrality } \\
\cline { 3 - 4 } & $\begin{array}{l}\text {... in Downstream } \\
\text { Industry }\end{array}$ & $\begin{array}{l}\text {... in Upstream } \\
\text { Industry }\end{array}$ \\
\hline 1 & $\begin{array}{l}\text { lump-sum transfer to } \\
\text { households }\end{array}$ & none & none \\
\hline 2 & $\begin{array}{l}\text { economy-wide cuts in } \\
\text { labor and capital tax rates }\end{array}$ & none & none \\
\hline 3 & $\begin{array}{l}\text { economy-wide cuts in } \\
\text { labor and capital tax rates }\end{array}$ & $\begin{array}{l}\text { grandfathering of } \\
\text { pollution permits }\end{array}$ & none \\
\hline 4 & $\begin{array}{l}\text { economy-wide cuts in } \\
\text { labor and capital tax rates }\end{array}$ & none & $\begin{array}{l}\text { grandfathering of } \\
\text { pollution permits }\end{array}$ \\
\hline 5 & $\begin{array}{l}\text { economy-wide cuts in } \\
\text { labor and capital tax rates }\end{array}$ & $\begin{array}{l}\text { grandfathering of } \\
\text { pollution permits }\end{array}$ & $\begin{array}{l}\text { grandfathering of } \\
\text { pollution permits }\end{array}$ \\
\hline
\end{tabular}


Table 4: Numerical Results Under Central Case Parameter Values

Policy

Percent abatement

\section{Policy Instruments}

Permit price

Potential permit revenues

Compensation ratio $\mathrm{Y}$, gross

Compensation ratio $\mathrm{Y}$, ne

Compensation ratio $\mathrm{X}$, gross

Compensation ratio $\mathrm{X}$, net

Industry $X$

$\%$ change in output price

$\%$ change in $\mathrm{K}$ rental price

$\%$ change in $\mathrm{K}$ stocks

$\%$ change in employment

$\%$ change in output

\section{Industry $Y$}

$\%$ change in output price

$\%$ change in $\mathrm{K}$ rental price

$\%$ change in $\mathrm{K}$ stocks

$\%$ change in employment

$\%$ change in output

\section{Industry C}

$\%$ change in output price

$\%$ change in $\mathrm{K}$ rental price

$\%$ change in $\mathrm{K}$ stocks

$\%$ change in employment

$\%$ change in output

\section{Aggregate Factor Supplies}

$\%$ change in labor

$\%$ change in capital

\section{Efficiency Impact}

$\mathrm{EV}$ as \% of benchmark income
1

10

$$
\begin{array}{rrr}
0.10 & 0.26 & 3.85 \\
1.33 & 2.94 & 14.64 \\
-- & -- & -- \\
-- & -- & -- \\
-- & -- & -- \\
-- & -- & --
\end{array}
$$

$\begin{array}{lll}-0.90 & -2.17 & -13.89 \\ -1.07 & -2.56 & -16.21 \\ -1.03 & -2.47 & -15.63 \\ -2.09 & -4.95 & -29.21\end{array}$

$\begin{array}{lll}-2.09 & -4.95 & -29.21\end{array}$

$\begin{array}{lll}-1.20 & -2.87 & -17.93\end{array}$

$\begin{array}{rrr}0.65 & 1.59 & 12.66 \\ -0.53 & -1.28 & -9.25 \\ -0.49 & -1.19 & -8.62 \\ -0.09 & -0.22 & -1.65 \\ -0.59 & -1.44 & -10.44\end{array}$

$\begin{array}{rrr}-0.02 & -0.05 & -0.35 \\ -0.02 & -0.06 & -0.42 \\ 0.01 & 0.03 & 0.27 \\ 0.01 & 0.02 & 0.17 \\ 0.01 & 0.02 & 0.20\end{array}$

$\begin{array}{lll}0.00 & 0.01 \quad 0.11 \\ -0.03 & -0.08 & -0.52\end{array}$

$\begin{array}{lll}-0.03 & -0.08 & -0.52\end{array}$

$\begin{array}{lll}-0.23 & -0.78 & -10.81 \\ 0.00 & -0.01 & -0.17\end{array}$
10

$\begin{array}{llr}0.10 & 0.26 & 3.86 \\ 1.33 & 2.94 & 14.66\end{array}$

$\begin{array}{lrr}1.33 & 2.94 & 14.64\end{array}$

$\begin{array}{rrrrrr}-- & -- & -- & 31.48 & 38.14 & 109.16 \\ -- & -- & -- & -- & -- & --\end{array}$

$\begin{array}{lll}-- & - & - \\ - & - & -\end{array}$

$\begin{array}{lll}-0.91 & -2.17 & -13.90\end{array}$

$\begin{array}{lll}-1.07 & -2.56 & -16.22\end{array}$

$\begin{array}{lll}-1.03 & -2.46 & -15.60\end{array}$

$\begin{array}{lll}-2.08 & -4.94 & -29.18\end{array}$

$\begin{array}{lll}-1.19 & -2.85 & -17.89\end{array}$

$\begin{array}{lll}-0.91 & -2.17 & -13.89\end{array}$

$\begin{array}{lll}-1.07 & -2.56 & -16.21\end{array}$

$\begin{array}{lll}-1.03 & -2.46 & -15.63\end{array}$

$\begin{array}{lll}-2.08 & -4.94 & -29.21\end{array}$

$\begin{array}{lll}-1.20 & -2.86 & -17.93\end{array}$

\section{$\begin{array}{lll}0.65 & 1.59 & 12.67\end{array}$}

$\begin{array}{lll}-0.53 & -1.28 & -9.25\end{array}$

$\begin{array}{lll}-0.48 & -1.18 & -8.58\end{array}$

$\begin{array}{lll}-0.08 & -0.21 & -1.60 \\ -0.58 & -1.42 & -10.40\end{array}$

$\begin{array}{lll}-0.58 & -1.42 & -10.40\end{array}$

$\begin{array}{rrr}0.65 & 1.59 & 12.66 \\ -0.53 & -1.28 & -9.25 \\ -0.49 & -1.18 & -8.62 \\ -0.09 & -0.21 & -1.66 \\ -0.59 & -1.43 & -10.44\end{array}$

$\begin{array}{lll}-0.02 & -0.05 & -0.35\end{array}$

$\begin{array}{lll}-0.02 & -0.06 & -0.42\end{array}$

$\begin{array}{lll}0.02 & 0.05 & 0.32\end{array}$

$\begin{array}{lll}0.01 & 0.04 & 0.22\end{array}$

$\begin{array}{lll}0.02 & 0.04 & 0.25\end{array}$

$\begin{array}{lll}-0.02 & -0.05 & -0.35\end{array}$

$\begin{array}{lll}-0.02 & -0.06 & -0.42\end{array}$

$\begin{array}{lll}0.02 & 0.04 & 0.26\end{array}$

$\begin{array}{lll}0.01 & 0.03 & 0.16\end{array}$

$\begin{array}{lll}0.01 & 0.03 & 0.19\end{array}$

$\begin{array}{rrr}0.01 & 0.03 & 0.17\end{array}$

$\begin{array}{lll}0.01 & 0.02 & 0.11 \\ -0.03 & -0.07 & -0.52\end{array}$

$\begin{array}{lll}-0.03 & -0.07 & -0.52\end{array}$

$\begin{array}{lll}-0.08 & -0.48 & -9.92\end{array}$

$\begin{array}{lll}-0.14 & -0.61 & -10.88\end{array}$

$\begin{array}{lll}0.00 & -0.01 & -0.18\end{array}$
10

25

$\begin{array}{rrr}0.10 & 0.26 & 3.85 \\ 1.33 & 2.94 & 14.65 \\ -- & -- & -- \\ -- & -- & -- \\ 17.98 & 19.49 & 25.10 \\ 19.66 & 23.17 & 52.86\end{array}$

$\begin{array}{lll}-0.91 & -2.17 & -13.89\end{array}$

$\begin{array}{lll}-1.07 & -2.56 & -16.22\end{array}$

$\begin{array}{lll}-1.03 & -2.46 & -15.62\end{array}$

$\begin{array}{lll}-2.08 & -4.94 & -29.20\end{array}$

$\begin{array}{lll}-1.19 & -2.86 & -17.91\end{array}$

$\begin{array}{lll}-1.07 & -2.56 & -16.21\end{array}$

$\begin{array}{lll}-1.03 & -2.47 & -15.66\end{array}$

$\begin{array}{lll}-2.08 & -4.95 & -29.22\end{array}$

$\begin{array}{lll}-1.20 & -2.86 & -17.95\end{array}$

$\begin{array}{rrrrrr}0.65 & 1.59 & 12.67 & 0.65 & 1.59 & 12.66 \\ -0.53 & -1.28 & -9.25 & -0.53 & -1.28 & -9.24 \\ -0.49 & -1.18 & -8.60 & -0.49 & -1.19 & -8.65 \\ -0.09 & -0.21 & -1.63 & -0.09 & -0.22 & -1.69 \\ -0.58 & -1.43 & -10.42 & -0.59 & -1.43 & -10.47\end{array}$

$\begin{array}{lll}-0.02 & -0.05 & -0.35\end{array}$

$\begin{array}{lll}-0.02 & -0.06 & -0.42\end{array}$

$\begin{array}{lll}0.02 & 0.05 & 0.29\end{array}$

$\begin{array}{lll}0.01 & 0.03 & 0.19\end{array}$

$\begin{array}{lll}0.01 & 0.03 & 0.22\end{array}$

$\begin{array}{lll}-0.02 & -0.05 & -0.35\end{array}$

$\begin{array}{lll}-0.02 & -0.06 & -0.42\end{array}$

$\begin{array}{lll}0.02 & 0.04 & 0.23\end{array}$

$\begin{array}{lll}0.01 & 0.02 & 0.13\end{array}$

$\begin{array}{lll}0.01 & 0.02 & 0.13 \\ 0.01 & 0.03 & 0.16\end{array}$

$\begin{array}{rrrrrr}0.01 & 0.02 & 0.13 & 0.01 & 0.01 & 0.08 \\ -0.03 & -0.07 & -0.50 & -0.03 & -0.08 & -0.56\end{array}$

$\begin{array}{llllll}-0.03 & -0.07 & -0.50 & -0.03 & -0.08 & -0.56\end{array}$

$\begin{array}{rrrrrr}-0.12 & -0.56 & -10.44 & -0.17 & -0.70 & -11.42 \\ 0.00 & -0.01 & -0.17 & 0.00 & -0.01 & -0.18\end{array}$ 

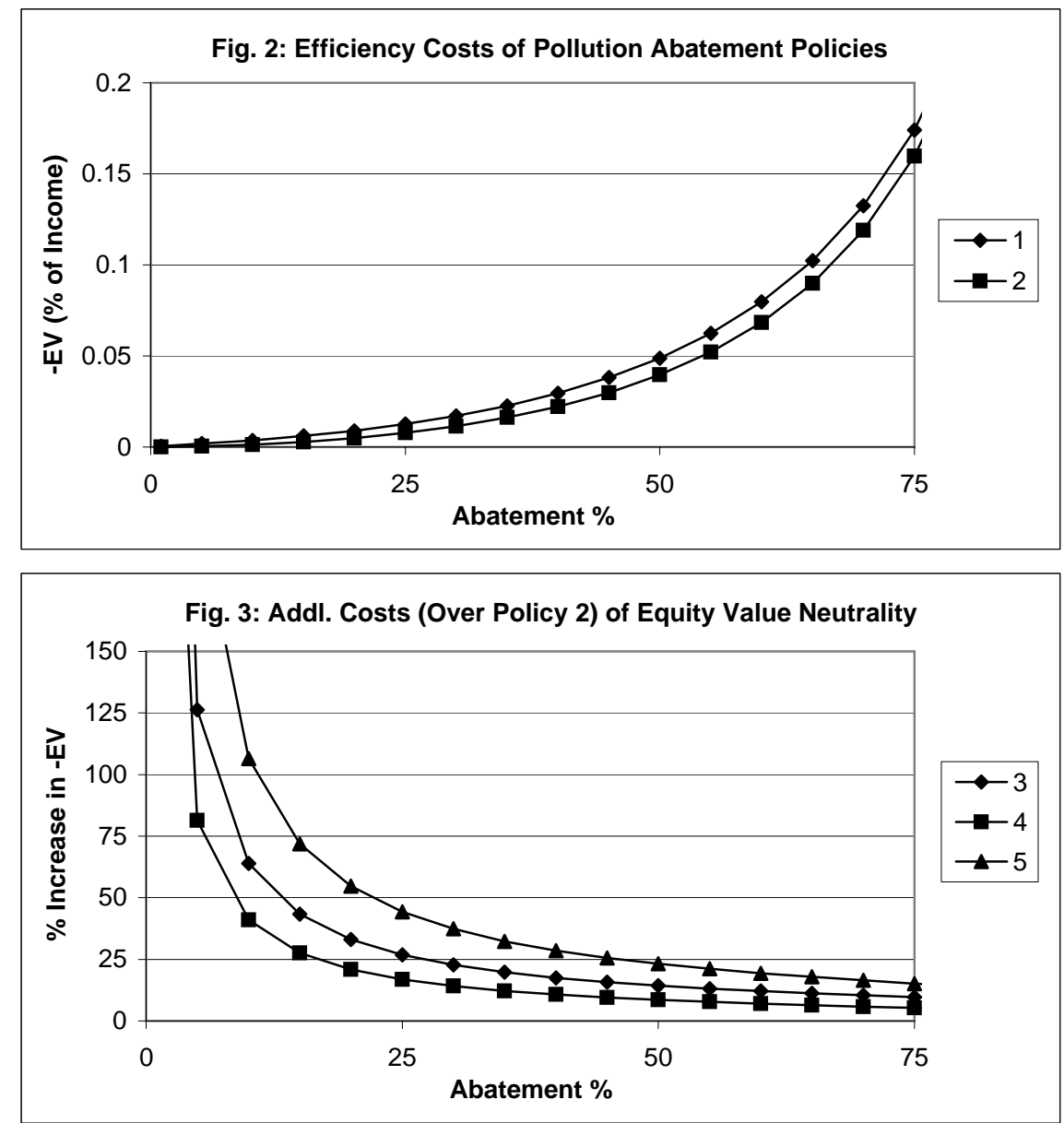

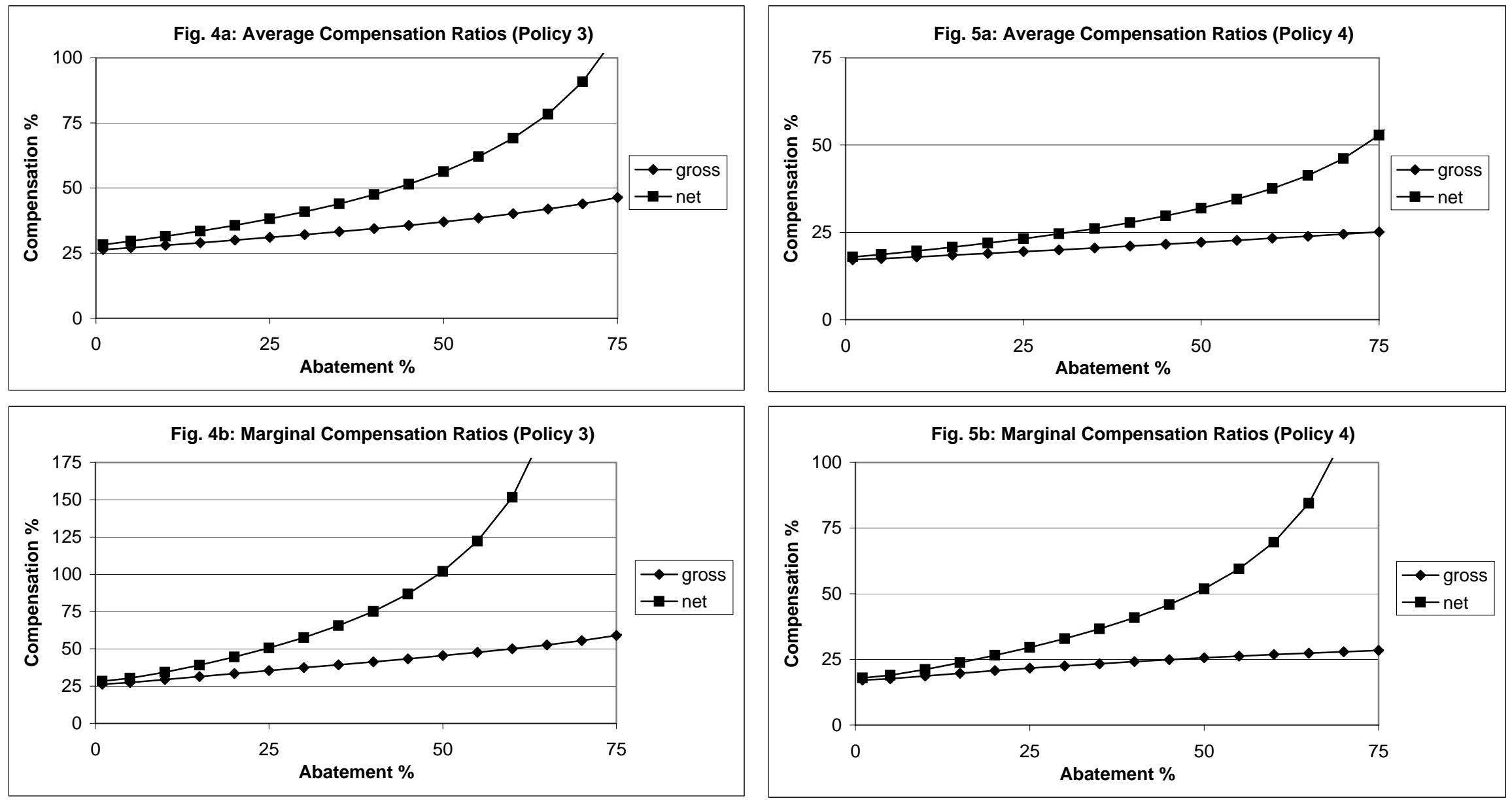
Table 5: Policy 2 Efficiency Costs -- Sensitivity Analysis (ratio of costs under alternative parameter value to costs in central case)

\section{Low parameter value}

Percent abatement

\section{Parameter varied}

EOP treatment $\left(\beta_{e}\right)$

Input substitution in $\mathrm{Y}\left(\sigma_{y}\right)$

Input substitution in $\mathrm{V}\left(\sigma_{v}\right)$

Consumption substitution $\left(\sigma_{g}\right)$

Labor substitution $\left(\sigma_{u}\right)$

Capital mobility $\left(\sigma_{k}\right)$
10

25

75

$7.96 \quad 9.88$

$1.00 \quad 1.00$

$1.02 \quad 1.02$

$1.02 \quad 1.02$

0.89

0.96
High parameter value

$\begin{array}{ccc}10 & 25 & 75 \\ 0.34 & 0.34 & 0.38 \\ 1.00 & 1.00 & 0.99 \\ 0.96 & 0.96 & 0.92 \\ 0.98 & 0.98 & 0.94 \\ 1.31 & 1.31 & 1.31 \\ 1.02 & 1.02 & 1.04\end{array}$



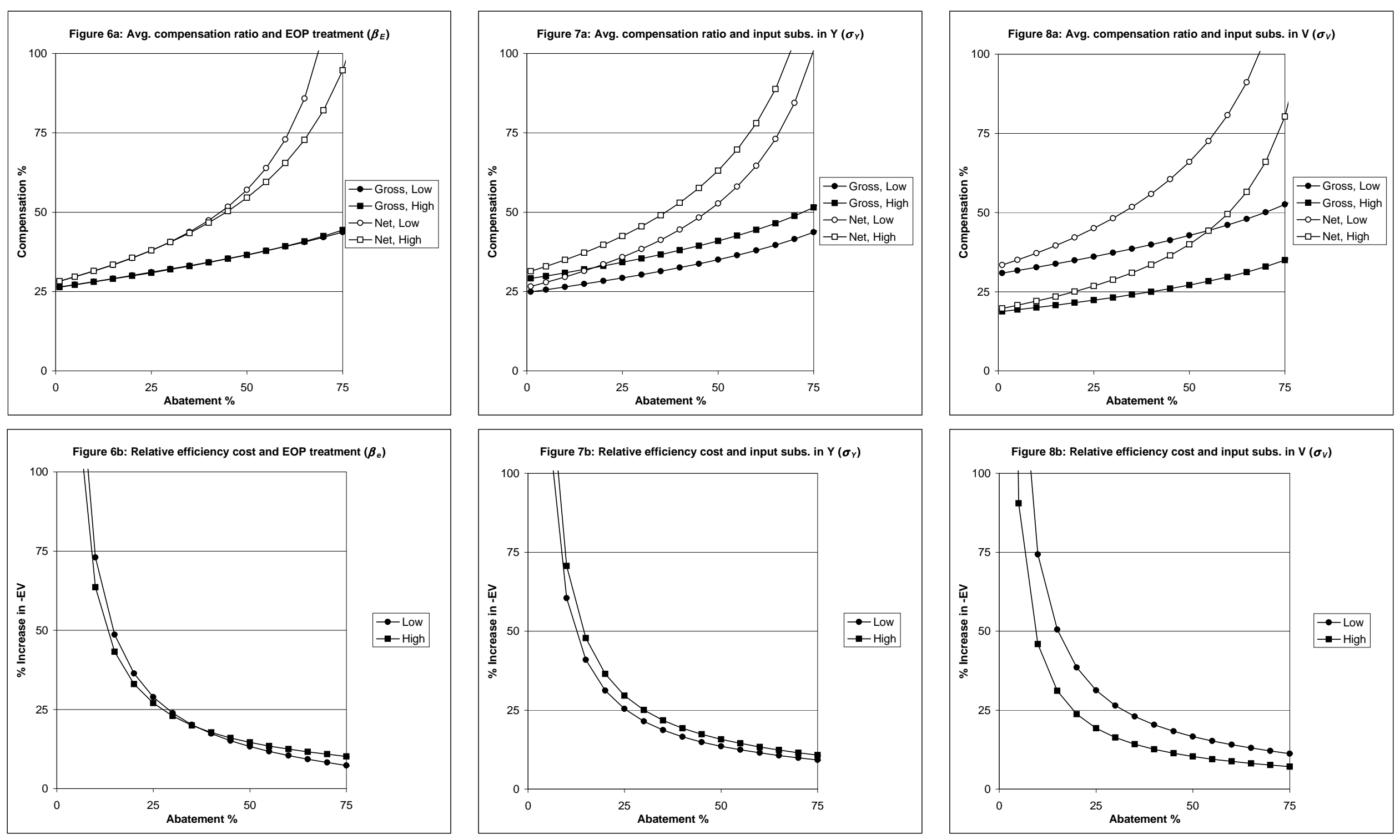

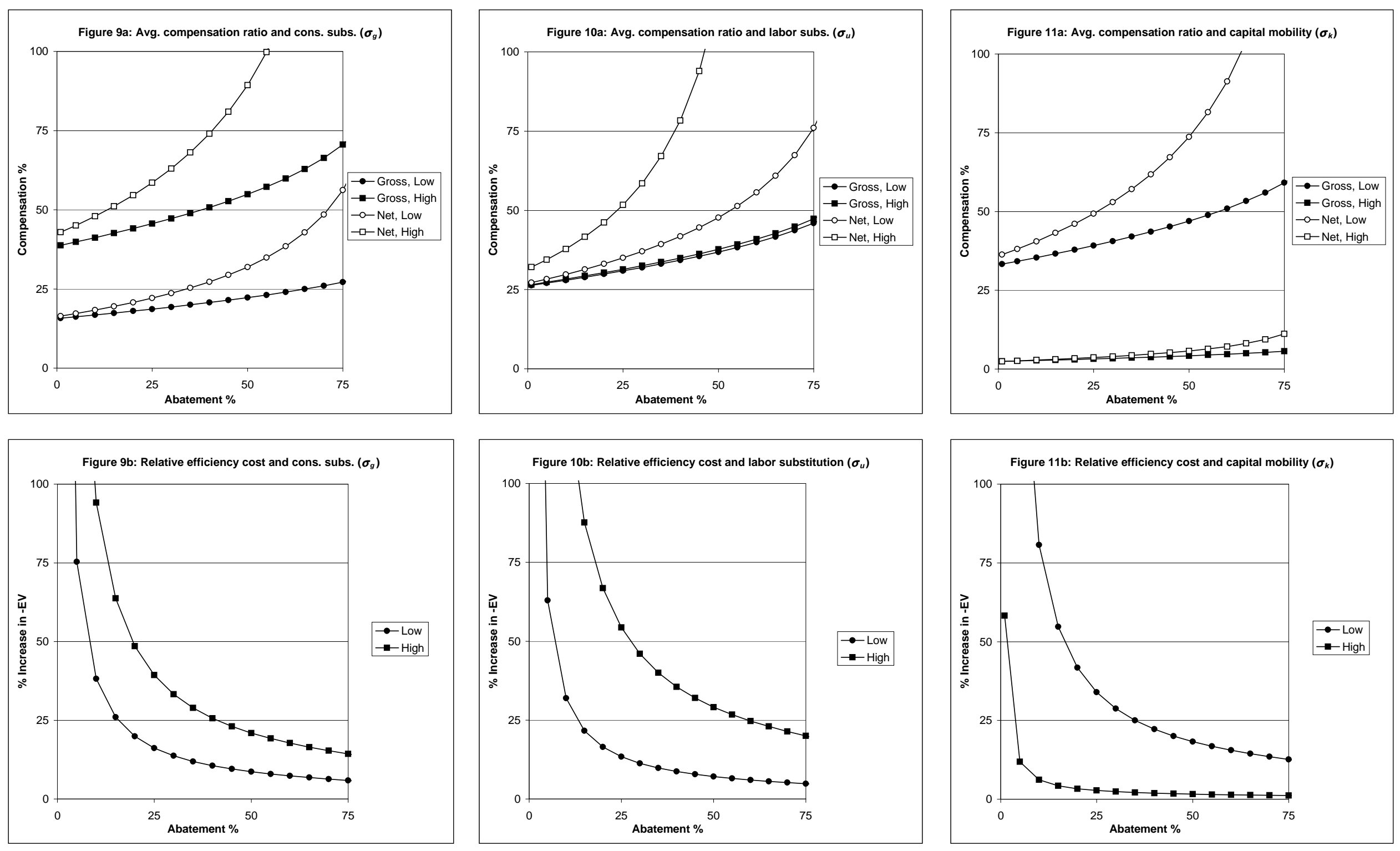